\title{
PLAN OR REACT? ANALYSIS OF ADAPTATION COSTS AND BENEFITS USING INTEGRATED ASSESSMENT MODELS
}

\author{
SHARDUL AGRAWALA*,\|, FRANCESCO BOSELLO ${ }^{\dagger, * * *}$,

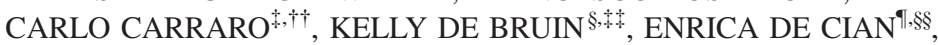 \\ ROB DELLINK*, $^{*}$, and ELISA LANZI*,|l|| \\ *OECD, 2, rue André Pascal - 75775 Paris Cedex 16, France \\ ${ }^{\dagger}$ University of Milan and Fondazione Eni Enrico Mattei \\ Isola di San Giorgio Maggiore, 30124 Venezia, Italy \\ University of Venice, CEPR, CESifo and Fondazione Eni Enrico Mattei \\ Isola di San Giorgio Maggiore, 30124 Venezia, Italy \\ ${ }^{\S}$ Umeå universitet, SE-901 87 Umeå, Sweden \\ "Fondazione Eni Enrico Mattei, Isola di San Giorgio Maggiore \\ 30124 Venezia, Italy \\ "shardul.agrawala@oecd.org \\ **francesco.bosello@feem.it \\ †carlo.carraro@feem.it \\ 椋kelly.debruin@econ.umu.se \\ §§enrica.decian@feem.it \\ "Trob.dellink@oecd.org \\ IIIIelisa.lanzi@oecd.org
}

\begin{abstract}
This report examines adaptation and mitigation within an integrated framework. Global and regional costs of adaptation are assessed dynamically and the resulting benefits are quantified. This is accomplished by developing a framework to incorporate adaptation as a policy variable within three Integrated Assessment Models (IAMs); the global Dynamic Integrated model of Climate and the Economy (DICE), the Regional Integrated model of Climate and the Economy (RICE), and the World Induced Technical Change Hybrid (WITCH) model. The framework developed here takes into account investments in reactive adaptation and in adaptation "stocks", as well as investments in building adaptive capacity. This report presents the first inter-model comparison of results on adaptation costs using the emerging category of adaptation-IAMs Results show that least-cost policy response to climate change will need to involve subsantial amounts of mitigation efforts, investments in adaptation stock, reactive adaptation measures and adaptive capacity to limit the remaining damages.
\end{abstract}

Keywords: Integrated assessment modeling; adaptation; adaptive capacity; climate change.

\section{Introduction}

Adaptation has been increasingly recognized as an important complementary response to greenhouse gas mitigation to address the risks posed by climate change. Significantly scaled up financing for adaptation is one of the key points of the international 
negotiations on climate change. Central to this policy imperative has been the need to get a better understanding of the costs and benefits of adaptation, particularly at the aggregate level. Consequently there has been considerable analytical effort in recent years in estimating the aggregate costs of adaptation (cf. UNFCCC, 2007; Stern, 2007; UNDP, 2007; Parry et al., 2009; World Bank, 2010).

While important from an agenda setting perspective, these estimates are typically static, do not differentiate between investments in various types of adaptation or quantify the resulting benefits, and do not consider the inter-relationships between adaptation and mitigation. Questions such as these can profitably be addressed within the context of integrated assessment modeling frameworks that explicit treat climate damage, mitigation costs, as well as adaptation costs. Such Integrated Assessment Models (IAMs) provide the type of framework required for an analysis characterizing the feedback between economic activity and emissions, climate change damages, and policy responses such as adaptation and mitigation.

IAMs have generally either overlooked adaptation entirely or treated it implicitly as part of the climate damage estimates (Fankhauser et al., 1999; Fischer et al., 2007). Hope et al. (1993) is the first paper that models adaptation within an IAM. Using the Policy Analysis for the Greenhouse Effect (PAGE) model, the authors look at two adaptation policy choices, namely no adaptation and aggressive adaptation, to find that an aggressive adaptation policy is beneficial and should be implemented. Although this analysis takes a step in considering adaptation and how it may be implemented into IAMs, adaptation is not a choice variable but a discrete variable linked to the scenarios. Furthermore, the effectiveness and costs of adaptation in the model are not based on empirical data and seem rather unrealistic. Adaptation is also explicitly modeled in the Climate Framework for Uncertainty, Negotiation and Distribution (FUND) model of Tol (2007), which is then used to examine tradeoffs between adaptation and mitigation. However, the treatment of adaptation in this analysis is only limited to coastal protection.

More recent papers have modeled adaptation as a policy choice variable covering a comprehensive amount of climate change impacts. De Bruin et al. (2009b) developed and tested a framework for the explicit incorporation of adaptation in the Dynamic Integrated Climate Economy (DICE) model (Nordhaus, 1994, 2007). A regional version was developed by de Bruin et al. (2009a, 2009c) based on the Regional Integrated Climate Economy (RICE) model (Nordhaus and Yang, 1996; Nordhaus and Boyer, 2000). In these models, i.e., AD-DICE and AD-RICE, total adaptation costs and benefits are estimated based on aggregated data from the literature. These models are then calibrated to replicate the original net damage function of DICE and RICE. The optimal level of adaptation is chosen considering the expenditures relative to avoided gross damages. While in these works adaptation is treated as a "flow" variable, i.e., all the costs and benefits accrued in the same time period, Bosello (2010) includes adaptation in the FEEM-RICE model (Bosetti et al., 2006a) treating it as a "stock" variable, where the benefits persist for decades into the future. To include a more comprehensive 
treatment of adaptation, recent works model both stock and flow forms of adaptation. De Bruin (2011) applies this enhanced framework to the AD-RICE model whilst Bosello et al. (2010) to the World Induced Technical Change Hybrid (WITCH) model (Bosetti et al., 2006, 2007, 2009) where they also add cumulated knowledge for adaptation.

These recent efforts to analyze interactions between mitigation and adaptation raise the question of whether policy-relevant results are robust to the use of different modeling frameworks. This paper proposes to study the interactions between flow and stock adaptation expenditures and mitigation in a comparative manner. In particular, the paper compares results between the AD-DICE and AD-WITCH models. The two models have substantive differences in the treatment of mitigation and adaptation costs and benefits. Both models include investments in stock and flow adaptation actions, but AD-WITCH also includes an explicit treatment of adaptive capacity in addition.

This paper contributes to the literature by distinguishing between robust and idiosyncratic results concerning adaptation and mixes between adaptation and mitigation. Although the two models provide a different characterization of adaptation and mitigation, other assumptions in the model such as data, climate module, and production function are similar. By varying only on the mitigation and adaptation assumptions we can single out their effects on results. Furthermore, the analysis and results presented here are exploratory. They do not represent exact policy prescriptions. The limited data and understanding of adaptation options requires bold assumptions, which is also the motivation behind this paper. Though the results presented are tentative, they show important mechanisms at work regarding adaptation and mitigation. They can give us insights into adaptation and mitigation decision making as well as indications of the order of magnitude of adaptation and mitigation expenditure needs.

The rest of this paper is organized as follows. Section 2 illustrates the modeling framework for incorporating stock and flow adaptation within the AD-DICE and ADWITCH models. Section 3 illustrates the result. Finally, Section 4 concludes.

\section{Modeling Framework}

AD-DICE and AD-WITCH are built on the DICE and WITCH models respectively. These are both dynamic Integrated Assessment Models of climate change in which in each time period, consumption and savings/investment are endogenously chosen in order to maximize intertemporal welfare subject to available income and affected by the costs of climate change. The two models share many common characteristics. They are based on a similar climate module that links greenhouse gases (GHG) emissions to GHG concentrations, and eventually to the global mean temperature increase compared to preindustrial levels. A reduced-form damage function translates the temperature increase to output losses.

The two models also have substantial differences. While DICE is a global model with a single representative consumer/producer, WITCH is divided in 12 world macro 
regions. ${ }^{1}$ Climate change damage as well as energy markets and innovation externalities are fully accounted for. Because individual regions optimize their own welfare, taking as given the choices made by the other regions, the decentralized solution represents a Nash equilibrium in which economic and environmental externalities are not internalized. In contrast, DICE provides a cooperative solution that is globally optimal because it maximizes global social welfare. ${ }^{2}$

Compared to DICE, WITCH provides a breakdown of the energy sector into different final uses (power generation and final use), different technologies, and different energy carriers. It includes $R \& D$ investments, which enhance energy efficiency and facilitate the introduction of innovative low carbon technologies. Whereas in DICE $\mathrm{CO}_{2}$ emissions are linked to production, in WITCH they are directly related to the use of fossil fuels through stoichiometric coefficients. Non- $\mathrm{CO}_{2}$ GHG are included in the WITCH model and their abatement is described through marginal abatement cost curves.

Given the different characterization of the energy sector and of the linkage between economic activity and emissions, the two models also differ in the way they represent mitigation policies for the stabilization of greenhouse gases emissions. In DICE emission reduction is a direct choice variable, given as a fraction of emissions reduced, with a corresponding mitigation cost function decreasing over time as technology advances. In the WITCH model, however, $\mathrm{CO}_{2}$ emissions depend on the chosen portfolio of different investments in energy technologies, innovation, and the final good. This influences particularly the results on mitigation costs and on the interactions between mitigation and adaptation. More precisely, while in DICE mitigation can be immediately implemented in any period; in WITCH it will follow investment choices.

Regarding adaptation, despite the similarities, there are several key differences between the models. The incorporation of adaptation is based virtually on the same data and both models include stock and flow adaptation. However, in the AD-WITCH model adaptation can be enhanced by investing in adaptive capacity. The following section describes in more detail the incorporation of adaptation in the two models.

\subsection{Modeling adaptation in the DICE and WITCH models}

Adaptation decreases the potential damage of climate change. This is the mechanism that is added explicitly in both AD-DICE and AD-WITCH. Gross damages are defined as the damages caused by climate change if no adjustments are made in ecological, social and economic systems. However, if these systems were to adapt, the observed

\footnotetext{
${ }^{1}$ USA, WEURO (Western Europe), EEURO (Eastern Europe), CAJAZ (Canada, Japan, New Zealand), CHINA (China and Taiwan), SASIA (South Asia), SSA (Sub-Saharan Africa), LACA (Latin America, Mexico, and the Caribbean), KOSAU (Korea, South Africa, Australia), TE (Transition Economies), EASIA (South East Asia), MENA (Middle East). ${ }^{2}$ The WITCH model can also provide a cooperative solution that internalizes all economic and environmental externalities, but in this paper we only allow for cooperation on climate change in the mitigation scenarios.
} 
climate damages would decrease. These "left-over" damages are referred to as residual damages. Reducing gross damages, however, comes at a cost, which is represented by the allocated resources to adaptation. These costs are referred to as adaptation costs. In this setting, net damages consist of the sum of residual damages and adaptation costs. The implicit assumption is that adaptation is indeed a policy variable. This can be debated, due to the private nature of many adaptation options (e.g., Tol, 2005). Although it can be argued that these adaptation decisions are private, many adaptation options are public. Furthermore, private adaptation undertaken in a region is still a decision taken within that region. ${ }^{3}$

The damage functions of the two IAMs examined increase exponentially with temperature, so that the higher the temperature, the higher the gross damages. This effect is stronger as higher levels of temperatures are reached. In the absence of adaptation, the net damage is higher, and corresponds to the gross damage. The gross damage can be reduced when adaptation activities are undertaken. Depending upon the amount of resources invested and how effective adaptation is a certain protection level will be achieved. ${ }^{4}$ With full protection, all gross damage is reduced, and there is no residual damage. When, instead, no protection is undertaken, all of gross damages remain. In this case, therefore, the gross and residual damages are the same. The protection level is expressed on a $0-1$ scale, with 1 implying that $100 \%$ of the gross damages were avoided. Implicitly, it is assumed that there is decreasing marginal damage reduction of adaptation costs. That is to say that the more adaptation is used the less effective additional adaptation will be, this is assumed as more efficient measures of adaptation will be applied first while less effective measures will be applied only later.

In the modeling framework implemented in AD-DICE and AD-WITCH the most effective adaptation measures will include a combination of reactive and proactive adaptation actions. From a modeling perspective, it is important to distinguish between adaptation investments where both costs and benefits accrue in the same time period and those where initial investments offer benefits that extend beyond the time period when the costs were incurred (Lecocq and Shalizi, 2007). In modeling jargon, the former can be termed flow adaptation and the latter stock adaptation. Flow adaptation generally falls within the category of reactive actions such as changes in agricultural practices, energy expenditures for space heating and cooling, and treatment of climate related diseases. Stock adaptation, meanwhile, is characterized by a build-up of investments in capital goods aimed at reducing the gross damage from climate change. Investments in coastal protection infrastructure such as sea walls, water storage and

\footnotetext{
${ }^{3}$ For an overview of limitations to adaptations and how these can be incorporated in IAMs, see de Bruin and Dellink (2011).

${ }^{4}$ The term "protection level" is a holdover from research in coastal zones, where the benefits of adaptation measures such as sea walls were quantified in terms of the level of protection they offered. In this paper (and in other literature), the term protection level is used in a much broader sense to indicate the ratio of gross damages that are avoided as a result of the adaptation measure.
} 
irrigation facilities, disaster early warning systems, are all examples of stock adaptation that require upfront investments that then offer a stream of benefits well into the future.

Stock and flow adaptations are closely intertwined and any sector is likely to have a combination of both measures. Flow and stock adaptations can also substitute each other to a certain degree, but are certainly not perfect substitutes. To illustrate this, consider the example of agriculture. Flow options are very important in this sector, where adjustments in crops and crop planting times and increased irrigation can decrease the losses due to climate change. Stock option can increase the effectiveness of reactive adaptation through the building of irrigation systems. Both flow and stock options will decrease damages, but for the most effective solution both are needed. In the current framework, stock and flow adaptation are assumed to be imperfect substitutes for each other. This is modeled combining them with a Constant Elasticity of Substitution (CES) function.

Besides stock and flow, another relevant distinction is between investments in adaptation actions (i.e., stock and flow adaptation) that directly help reduce the adverse consequences of climate change impacts (or help capitalize on beneficial opportunities) from investments in adaptive capacity. The IPCC Fourth Assessment Report defines adaptive capacity as "the ability of a system to adjust to climate change (including climate variability and extremes) to moderate potential damage, to take advantage of opportunities, or to cope with the consequences" (IPCC, 2007). Adaptive capacity is vital for effective adaptation responses, and, therefore, another component of the adaptation "bill".

The AD-WITCH model considers the role of adaptive capacity in enhancing effectiveness of both stock and flow adaptation activities. This includes specific adaptive capacity that targets adaptation to climate change (e.g., investments to offset climate change impacts, $\mathrm{R} \& \mathrm{D}$ for drought resistant crops) as well as more generic capacity (e.g., income, education, improved sanitation and public health infrastructure) that is more broadly linked to development but will nevertheless contribute to enhancing the efficacy of downstream adaptation actions. Generic adaptive capacity captures components not necessarily related to adaptation itself but to the economic development of a region. The level of development influences the possibilities to adapt, with richer regions having more possibilities and pre-existing human capital and knowledge to engage in adaptation activities. Indicators of capacity specific to a particular impact may relate to specific infrastructure, knowledge, and technology.

In the framework developed for AD-WITCH, agents choose between investing in adaptation actions and building adaptive capacity. Within adaptation actions, meanwhile, it is possible to choose between stock and flow adaptation, like in the AD-DICE model. These are considered to be substitutes, although substitutability is slightly less than in the AD-DICE model (see Appendix A). Adaptive capacity is then composed of generic and specific adaptive capacity. Generic and specific capacity are considered to be complements, reflecting the idea that any specific intervention (e.g., effective introduction of new crop varieties, effective implementation of early warning systems) 


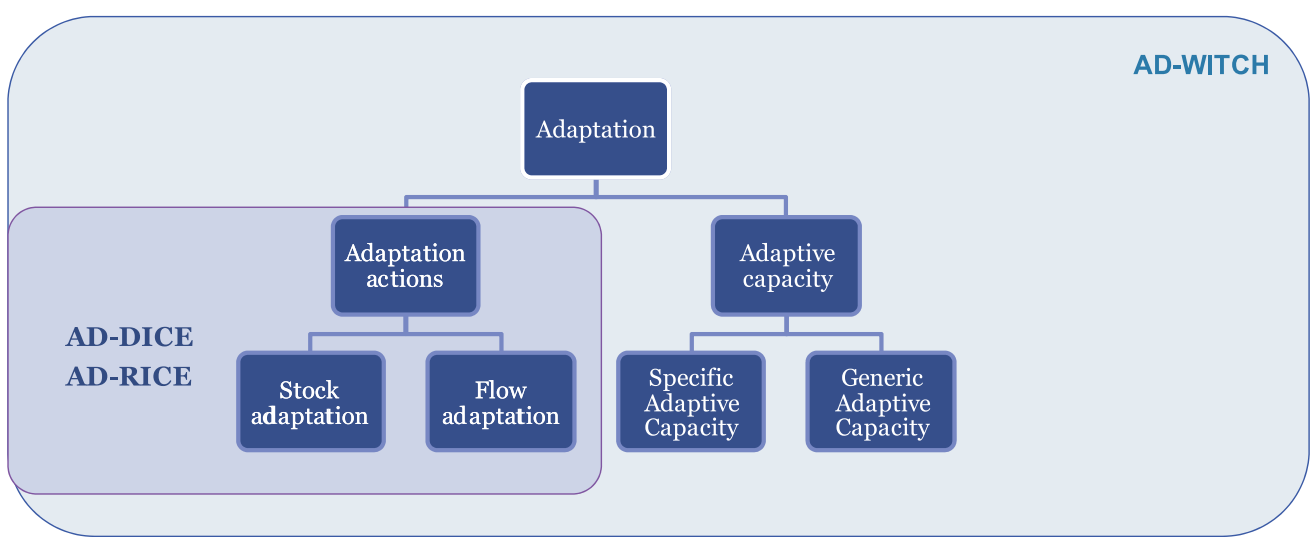

Figure 1. Types of adaptation included in the AD-DICE and AD-WITCH models.

requires some minimum conditions in terms of training, institutions, overall development, and political stability. As a consequence, both generic and specific adaptive capacities work together to improve the effectiveness of adaptation actions. ${ }^{5}$

Figure 1 illustrates the different adaptation activities that can be undertaken in the AD-WITCH model, as well as the subset of activities that can be chosen in the ADDICE model. The figure illustrates the different types of activities, namely adaptation strategies and adaptive capacity. The former is in turn divided between stock and flow adaptation, while the latter between specific and generic adaptive capacity.

In each time period, the optimal level of flow adaptation and of investments in stock adaptation (and specific adaptive capacity) will be chosen. The choice of these variables determines the protection level, the residual damage, and the level of adaptation stock (and adaptive capacity).

There are a number of differences in the way adaptation has been incorporated into the models considered. AD-DICE assumes that both adaptation costs and benefits are given as a fraction of GDP. The costs are a direct function of GDP and adaptation reduced damages are also given as a fraction of GDP. In AD-WITCH, however, adaptation benefits are assumed to be a function of GDP and adaptation costs are in absolute dollar terms. Arguments can be given to support both these assumptions. ADWITCH assumes that the same dollar investment in adaptation will decrease the same fraction of GDP over time. This is based on the argument that as GDP rises, more can be protected with the same adaptation measure. For example, the same dyke can protect an increasingly valuable settlement behind it. AD-DICE assumes that the costs of adaptation measures will also increase as GDP increases over time. First, it can be argued that the costs of building and implementing adaptation measures will increase as GDP increases. Second, as GDP increases over time so will the temperature, making

\footnotetext{
${ }^{5}$ This modeling choice follows the approach used in the WITCH model to describe endogenous technical change, based on Popp (2004).
} 
adaptation more costly. The two mechanisms behind these assumptions are valid and the final effect is debatable. This is why it is interesting to investigate how these assumptions will affect the results obtained.

The models also differ in the assumptions on the levels of substitutability between the different types of adaptation expenditure. In particular, AD-WITCH assumes lower possibilities to substitute. The exact effects of this assumption are hard to discuss as AD-WITCH has a more complex framework including nested substitution functions. Finally, there are differences in the parameters expressing the relationship between gross damage and temperature changes. A more technical description of the framework used to incorporate adaptation in the DICE and WITCH models is provided in Appendix A.

\subsection{Calibration of the models}

The DICE and WITCH models rely on the underlying climate damage function developed by Nordhaus and Boyer (2000). The DICE2007 model, which is used here to develop AD-DICE, has updated global damage estimates that are significantly higher than those reported in Nordhaus and Boyer (2000). AD-WITCH also considers new information coming from more recent literature on the different types of damages to calibrate the model for the different regions.

The net damages of Nordhaus and Boyer (2000) consist of residual damages, stock adaptation costs, and flow adaptation costs. These components have been explicitly separated using the relevant literature or expert judgment on the levels of the relevant adaptation costs and benefits in each category. A key input to this is the assessment of adaptation costs and benefits previously conducted by Agrawala and Fankhauser (2008). Besides estimating these variables it is also necessary to estimate the levels of gross damages. This is done by estimating the effectiveness of the different forms of adaptation. That is how much of the gross damages can be reduced through adaptation in each sector. This allows for a better understanding of the damage in absence of adaptation and the benefits of adaptation. The AD-DICE and AD-WITCH models have been calibrated to replicate these estimates. There are differences in data sources and assumptions between the two models (see Appendix B). In AD-DICE expenditure for each damage category is also split in flow and stock adaptation. In AD-WITCH instead only the prevalent expenditure type is considered, so that some categories belong to flow adaptation, other to stock or adaptive capacity.

The damage categories used in AD-DICE and AD-WITCH are the same as in Nordhaus and Boyer (2000): Agriculture, Other Vulnerable Markets, Coastal, Health, Non Market Time Use, Catastrophic Events, and Settlements. Nevertheless, the sectoral aggregation is not made explicit in the study. It should be kept in mind that applying aggregated damage functions requires many assumptions. In particular, the total amount of adaptation efforts (especially investments) is assumed to be optimally allocated between the sectors; and within the sectors in turn the resources are optimally allocated between the different adaptation projects. The relative 
importance of each category in total damages is derived from the RICE99 model. Although the total level of damages for both models is based on the DICE2007 model, which has considerably higher damages than the RICE99 model (60\% increase), the damage categorization of the RICE model gives a good starting point to estimate the effects of adaptation. The costs and benefits of adaptation in each category are assessed based on available literature.

In the Agriculture category estimates are based on studies done on crop yield variation under different temperatures and precipitation. To assess adaptation in this sector, estimates of adaptation costs and benefits developed by Tan and Shibasaki (2003) are used. This type of adaptation action in agriculture can be classified as a flow activity. There are also investments in stock adaptation activities that can be done in agriculture, related to water supply and irrigation systems. These are also included in the agriculture category in the AD-DICE model, but not in the AD-WITCH model where they are instead classified under water protection activities in the Other Vulnerable Markets category.

In the Coastal category, options for sea level rise consist of either building sea walls to protect against sea level rise (incurring costs) or accepting the land loss (incurring residual damages). To estimate adaptation in this sector AD-DICE uses results from the FUND model (Tol, 2007). This provides estimates of the optimal protection level and costs and benefits of adaptation for more than 200 countries. The AD-WITCH model bases its estimates on the DIVA model. In AD-WITCH expenditure to limit coastal damages is modeled as stock adaptation, as it requires high investments for the construction of big infrastructures. This type of adaptation expenditure has a very high efficiency. In AD-DICE flow, adaptation is also considered, generally in the form of migration but is relatively small compared to the optimal expenditure on seawalls.

In the Health category adaptation is estimated using results from Murray and Lopez (1996) on general improvements in health care for AD-DICE and on Tol and Dowlatabadi (2001), who assesses the costs of the illnesses for different temperature scenarios, for AD-WITCH. Both models also use data from the WHO malaria report (WHO, 2008), which estimates the use of mosquito nets. As this is mostly a reactive type of adaptation, in AD-WITCH it is modeled as a flow variable. In AD-DICE, meanwhile, both stock and flow are considered, as in developing regions extra investments in healthcare infrastructure can decrease the occurrence of diseases and improve their treatment.

For the Settlements category, including both human settlements and ecosystems, both AD-DICE and AD-WITCH start from the work of Nordhaus and Boyer (2000), but attempt to separate settlements from ecosystems. In this formulation, settlements are assumed to have a higher adaptation potential than ecosystems, but they can adapt only at very high costs. The level of adaptation is low in developing regions, but higher in developed ones. In the AD-WITCH, this damage category is modeled as stock adaptation, as settlements adaptation requires the creation of new infrastructures. In AD-DICE, both forms are included, but stock adaptation plays a more significant role. 
The Other Vulnerable Markets (OVM) category refers to the effect of climate change on other markets, namely energy and water. More energy will be needed in some regions for air conditioning whereas colder regions will need less energy for heating. Estimates for energy demand are based on recent literature (Fankhauser, 1995; Mendelsohn, 2000; Rosenthal et al., 1995; De Cian et al., 2007). Water use is also expected to increase, for example, due to increased irrigation needs. Estimates for water use are based on the work by Kirshen (2007), who proposes an estimate of the investment needed to meet projected water demand in 2030 consistent with IPCC B1 and A1 scenarios in eight world regions. In the AD-WITCH model, the expenditure in space heating and cooling relative to the changes in energy demand is modeled as a flow variable, as changes in the use of heating and cooling devices will be reactive to the actual temperature. Water protection and use activities instead are modeled as a stock variable, as infrastructures are needed for consistently, changing water use. In AD-DICE, both flow and stock adaptation play a role. In certain situation investments in energy supply will be needed to insure energy supply as demand increases. However, most adaptation will be in the flow form as energy use will be increased applying existing energy infrastructure. It is assumed that in developing regions the adaptation costs will be higher especially in the case of stock adaptation.

Non Market Time Use is a more abstract category and refers to the change in leisure activities. Most regions have benefits in this category. Estimates for this sector rely on expert judgment to estimate the adaptation variables. Most of the impacts in this category will be adaptation costs as people will adapt their leisure activities to fit the new climate. Most of the expenditure will be done reactively, so that in ADWITCH this is modeled as flow adaptation. AD-DICE also includes a relatively small proportion of stock adaptation, as in some cases, infrastructure investments will be needed to sustain leisure activities.

The Catastrophic Events category refers to the Willingness To Pay (WTP) to avoid catastrophic events. ${ }^{6}$ These can be prevented through knowledge of the forthcoming disaster (early warning systems, scientific research, etc.). The main data source for this damage category is the study by Adams et al. (2000), which finds that early warning systems can be very effective for extreme events. However, this study is specifically focused on early warning systems in Mexico and in the agricultural sector. Thus, the efficiency of adaptation expenditure in this category is limited to a low level. In ADWITCH expenditure to limit the damages from extreme events is modeled as specific adaptive capacity. In AD-DICE adaptation is included in both the flow form, such as disaster relief, and in the stock form, such as early warning systems.

The Adaptive Capacity category included in the AD-WITCH model consists of two components, which have been calibrated as follows. Generic capacity is assumed to

\footnotetext{
${ }^{6}$ Note that although these are deterministic models and do not include an explicit treatment of probability, the estimates relative to the extreme event damage category take into account the uncertainty in the actual manifestation of these events.
} 
evolve exogenously with the growth rate of total factor productivity. The initial value is an indicator of local capacity based on human capital and knowledge stock. Specific capacity includes all forms of expenditure, investments, and institutions that could increase the adaptive capacity of a system and thus make adaptation activities more effective in reducing climate change damages. There are serious data constraint problems in the calibration of this variable, which was calibrated to be an arbitrarily low share of total world expenditure on education and total R\&D. The share was set to $1 \%$, corresponding to USD 164 billion in 2060. This global amount has then been distributed to the different regions according to the normalized share of education expenditure over GDP.

The differences in assumptions between the models, what data they use for calibration, and how they distinguish between stock and flow adaptation in various damage categories are all very relevant for the results. AD-DICE often includes stock adaptation where AD-WITCH does not. AD-WITCH, however includes adaptive capacity, which can be viewed as another form of stock adaptation. Detailed data on the costs, effectiveness of adaptation expenditure, and aggregation of damages are provided in Appendix B. The models have been calibrated on similar baselines, as illustrated in Appendix C. The baselines of the AD-DICE and AD-WITCH models fall within the commonly used Special Report on Emissions Scenarios (SRES) ${ }^{7}$ range and are close to the B scenarios.

\section{Results and Models Comparison}

This section will present results on the relative contribution of stock and flow adaptation and adaptive capacity, on climate change costs and on the interaction between mitigation and adaptation. In order to guarantee that overall policy messages are clear and robust, all results will be illustrated comparing AD-DICE with AD-WITCH.

\subsection{Composition of climate change costs}

Adaptation can significantly reduce the damages resulting from climate change, but it comes at a cost. Cost-benefit considerations determine the optimal adaptation effort. Figure 2 focuses on the case in which the mitigation effort is null and shows the results from optimal adaptation in the AD-DICE and AD-WITCH models. It is important to clarify the meaning of this scenario in the two models. In AD-WITCH, it mimics a world in which there are no international agreements on emission reduction and the

\footnotetext{
${ }^{7}$ Climate models are usually run against scenarios that reflect different levels of human activity. The various SRES scenarios are based on different assumptions on future pollution, land use, and other driving forces. The A2 scenario reflects a divided world in which nations are self-reliant, economically oriented, and not environment-focused. The B1 scenario reflects instead a more integrated and ecologically friendly world in which there is resource-saving technical change, and a slower population growth. Finally, the B2 scenario is also ecologically friendly, but with less coordination between countries and more focus on local solutions.
} 


\section{AD-DICE}
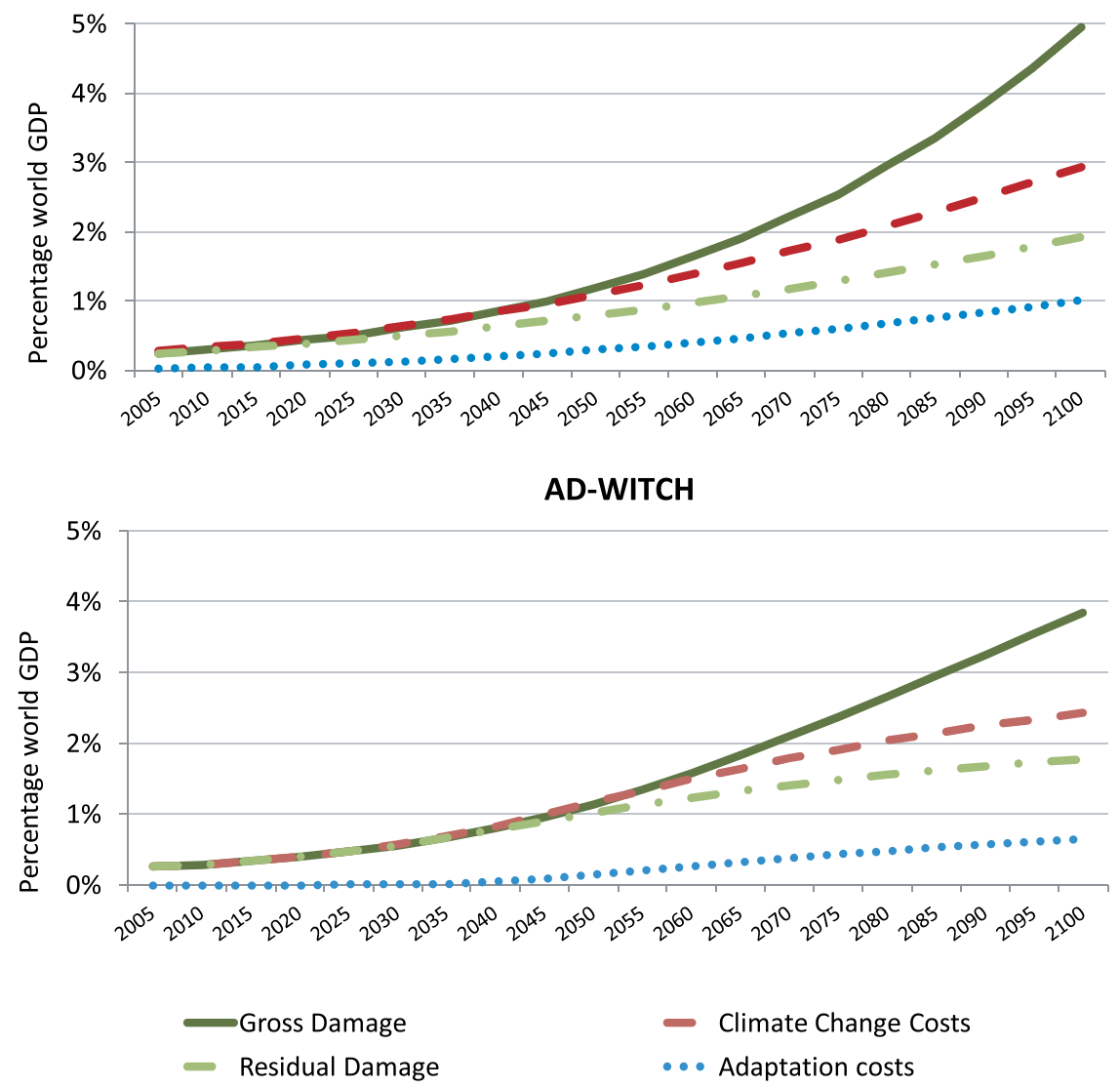

Figure 2. Composition of climate change costs under optimal adaptation and no mitigation.

free riding incentive prevails. This leads to the well-known tragedy of commons in which regions do not undertake any mitigation effort. In contrast, the AD-DICE model still adopts the perspective of a global social planner, but in the hypothetical case of no climate change damages. In this case, emission reduction is still undertaken as fossil fuels become increasingly expensive. Adaptation is optimally implemented as a response to global climate change damage in AD-DICE and as a response to regional climate change damages in AD-WITCH.

In absence of adaptation the gross damages are higher than net damages, which include the sum of residual damages and of adaptation costs. The gross damages and net damages in AD-DICE amount respectively to 5\% and 3\% of world GDP in 2100, whereas in AD-WITCH they are around $4 \%$ and $2.5 \%$ respectively. The two models diverge after the calibration point, 2065 in AD-WITCH and 2095 in AD-DICE, when the temperature increases above the preindustrial levels by 2.5 degrees. The AD-DICE calibration point is later as it is calibrated in the global optimal scenario as opposed to the Nash scenario in AD-WITCH. The damages differ to the different data sources used. 

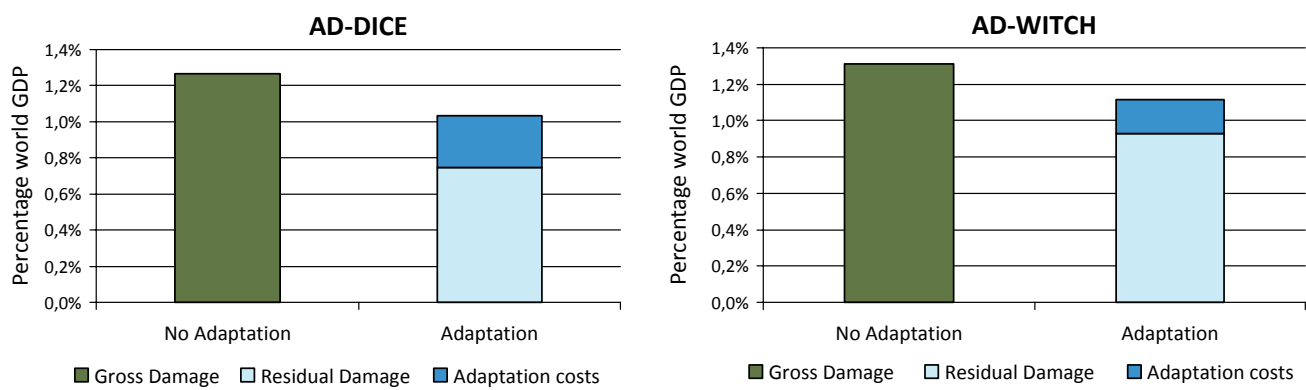

Figure 3. Composition of climate change costs under optimal adaptation and no mitigation (NPV of climate change costs as percentage of NPV of GDP) (2010-2100 3\% discounting).

AD-DICE applies the DICE2007 estimates of net damages, whereas AD-WITCH adjusts these damages in their calibration.

The Net Present Value (NPV) ${ }^{8}$ of costs over the current century, as illustrated in Fig. 3, shows that overall climate change costs with no adaptation are higher (i.e., the NPV of gross damages is higher than the NPV of the sum of residual damages and adaptation costs). Investments will need to be made in earlier years, even though the benefits are only reaped in later periods.

The costs of adaptation are $0.28 \%$ and $0.19 \%$ of world GDP in the AD-DICE and AD-WITCH models respectively. The benefits from adaptation (calculated as difference in between the gross and net damages) are $0.51 \%$ and $0.38 \%$ world GDP respectively. Therefore, the net benefits of adaptation are $0.23 \%$ of world GDP in AD-DICE and $0.20 \%$ of world GDP in AD-WITCH. The benefit-cost ratio of adaptation is greater than 1 for both models (1.80 in AD-DICE and $2.03 \mathrm{AD}-\mathrm{WITCH}) .^{9}$ Thus adaptation is cost-effective in both cases, and in particular the benefits are approximately double the costs. As a consequence of the reduction of climate change costs, adaptation also results in an increase in world output. Output increases by 1.4\% in AD-DICE and by $0.5 \%$ in $\mathrm{AD}-\mathrm{WITCH}$. As more damages are reduced in AD-DICE, there is also a higher welfare gain in that model.

\subsection{Composition of adaptation costs}

Flow and stock adaptation, as well as specific adaptive capacity can be expected to contribute to adaptation in different ways, as the different duration of the benefits influences the decision to invest. Figure 4 illustrates stacked investments in stock and flow adaptation and in specific adaptive capacity over time. The figure also shows snapshots of the relative contribution of the different types of adaptation expenditures for the years 2035, 2070, and 2100 to show how the mix changes over time.

\footnotetext{
${ }^{8}$ The Net Present Value (NPV) is a method for evaluating the profitability of an investment or project. The net present value of an investment is the present discounted value of present and future cash flows.

${ }^{9}$ These benefit-cost ratios can be considered as an upper bound as they correspond to a no-mitigation scenario.
} 

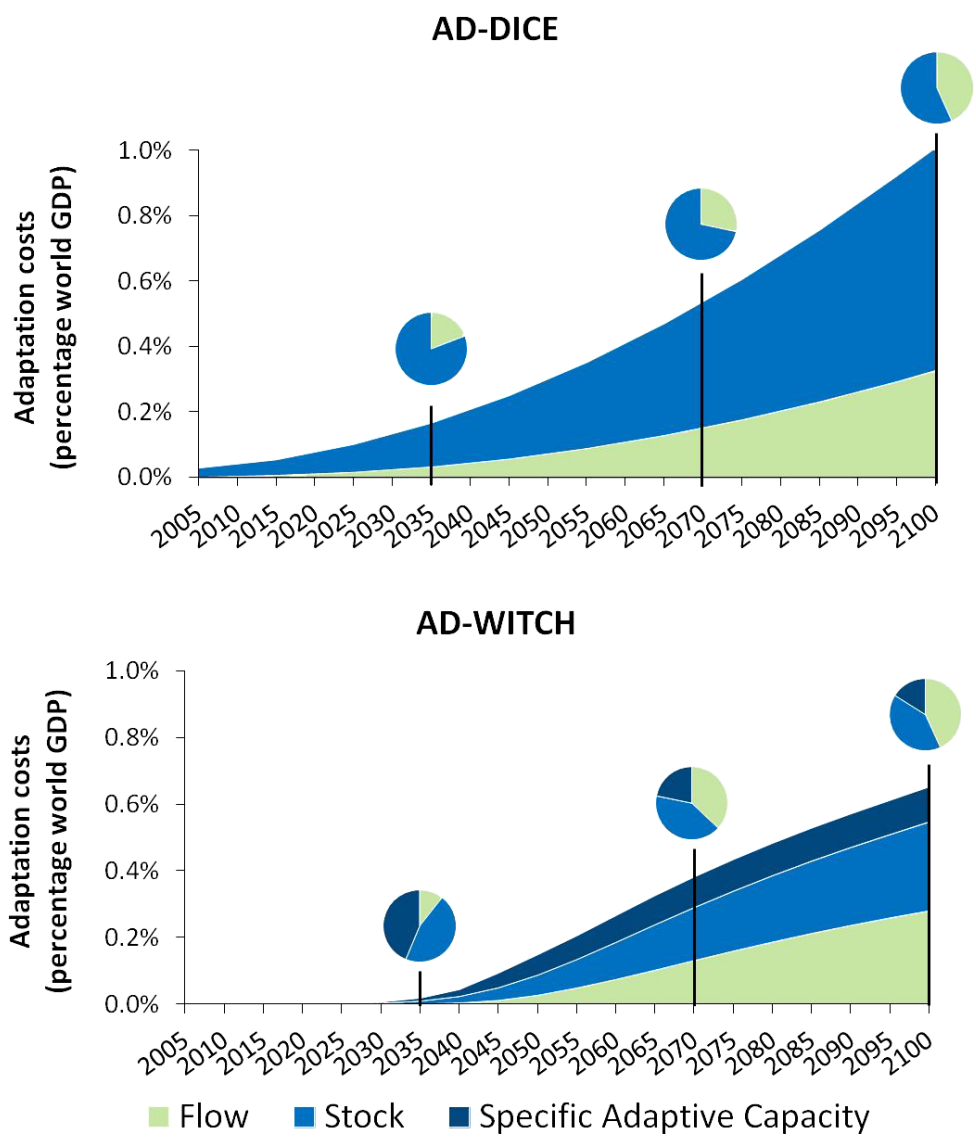

Figure 4. Breakdown of adaptation cost components.

As shown in Fig. 4, the total adaptation costs build up slowly in the first few decades of this century but rise as climate damages increase in the latter half of the century. In the year 2100 , the total adaptation costs will range from $0.6 \%-0.8 \%$ of world GDP in the AD-WITCH and AD-DICE models respectively. Early adaptation measures are higher in AD-DICE: in AD-DICE adaptation starts immediately, even if at low levels, whereas in the AD-WITCH model it begins to emerge only after around 2025. This is a consequence of the assumptions on the adaptation costs over time in the models. As GDP increases, adaptation benefits also increase, while costs remain unchanged. Due to the calibration of the AD-WITCH model, this makes adaptation in earlier time periods very expensive compared to later periods. Furthermore, in ADWITCH, where the level of GDP is included in general adaptive capacity, adaptation is implemented later, when general adaptive capacity is higher.

AD-DICE and AD-WITCH show similar patterns in terms of the overall mix of adaptation strategies. Both stock and flow forms of adaptation are important, although investments in stock adaptation (and specific adaptive capacity) tend to dominate for much of this century. There is also a difference in timing between stock and flow 
adaptation. Investments in stock adaptation start at an earlier date. This is because there is some time delay between the investments in stock adaptation and the realization of benefits. As such they are anticipatory investments. Further, the benefits from stock adaptation last longer. For both these reasons, it is reasonable to invest at an earlier date.

As illustrated by the pie charts embedded in Fig. 4, stock adaptation constitutes almost $80 \%$ of the optimal adaptation mix for AD-DICE in the year 2035, and drops to about $60 \%$ by the end of the century. In the case of AD-WITCH, investments in stock adaptation are lower and they constitute approximately $45 \%$ of the optimal adaptation mix throughout the century. The different mix is due to the broader adaptation portfolio available in the AD-WITCH model, where investing in specific capacity is an additional option that increases the effectiveness of both stock and flow measures. In fact, specific adaptive capacity constitutes almost $45 \%$ of the optimal adaptation mix in the year 2035, dropping to about $15 \%$ by the end of the century. The prevalence of stock adaptation costs is also due to the higher cost of stock adaptation actions. This is reflected in the parameter values of the CES functions.

These results offer important pointers for allocation of adaptation financing. Specifically, sufficient upfront investments in adaptation infrastructure and in building up adaptive capacity should be important components of an overall investment strategy in addition to more reactive measures. The results also open the question on how it will be possible to raise the necessary funding and what is the role of policy makers in inducing the investments. This question, which has been addressed by Agrawala and Fankhauser (2008), cannot be directly addressed in the present modeling environment as a global or at best regional models cannot include all possible local adaptation policies. Nevertheless, the result that both stock and flow types of adaptation will be fundamental suggests that public investment from state budget will be needed, especially for infrastructural projects, as well as the implementation of adaptation by private actors, in the case of more reactive measures.

\subsubsection{The role of discount rates}

The level and composition of adaptation costs depends upon the choice of the discount rate in the underlying models. Since both models are based on the optimal growth, Ramsey framework, the discount rate directly depends on the pure rate of time preference (PRTP) and the elasticity of marginal utility. The choice of the correct PRTP that discounts the welfare of future generations relative to the present one is an important topic of debate in the climate change literature. Both AD-DICE and ADWITCH use the PRTP proposed by Nordhaus and Boyer (2000) of 3\% declining over time. Sensitivity of the results to lower discounting is checked by applying a very low PRTP of $0.1 \%$, as proposed by Stern (2007).

Applying a lower pure rate of time preference makes agents more far-sighted and therefore more likely to invest in stock adaptation and in building adaptive capacity that offer delayed benefits. This is illustrated in Fig. 5 that shows the composition of 


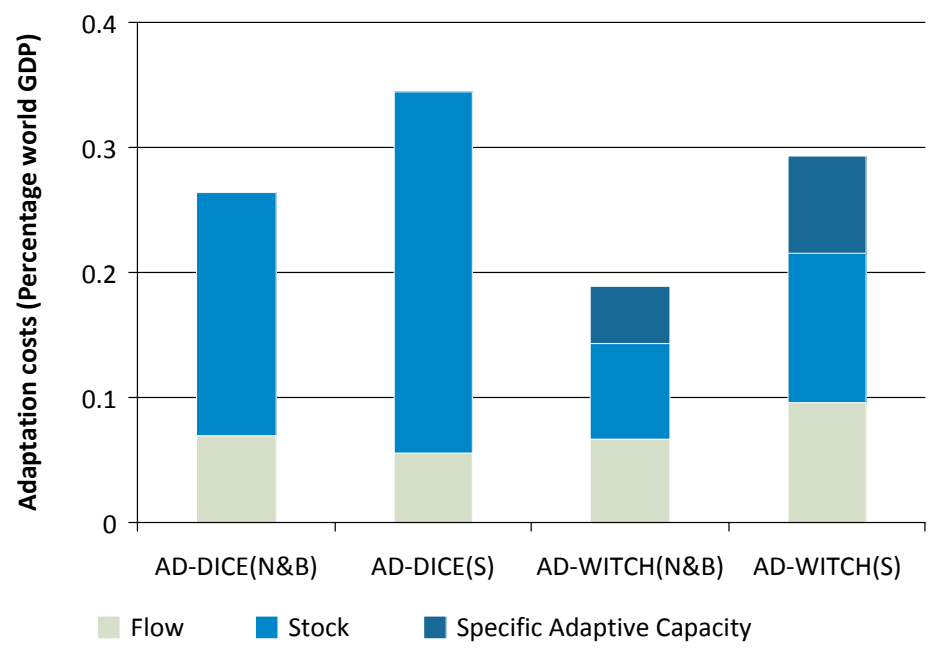

Figure 5. Adaptation strategy mix for different models and discount rates (NPV of climate change costs as percentage of NPV of GDP) (2010-2100 3\% discounting).

adaptation costs (in Net Present Value) in AD-DICE and AD-WITCH under the high Nordhaus and Boyer (N\&B) and low Stern (S) discount rates. Under the Stern discount rate, stock adaptation constitutes almost $82 \%$ of the adaptation costs in AD-DICE, an almost $20 \%$ increase compared to when the Nordhaus and Boyer discount rate is used. Likewise, in the AD-WITCH model, investments in stock adaptation and adaptive capacity under the Stern discount rate constitute almost 55\% of the adaptation mix, a $10 \%$ increase compared to when the Nordhaus discount rate is used.

Lower discount rates would tend to increase adaptation expenditure as well as to relatively redistribute more resources from reactive adaptation towards more proactive investments in building adaptation stock and adaptive capacity. Therefore, investments in adaptation stock and in building adaptive capacity behave more like investments in mitigation (as opposed to flow adaptation) due to the need for upfront investment and lagged benefits.

\subsubsection{The dynamics of adaptive capacity}

Using the AD-WITCH model interesting insights can be gained on the dynamics of adaptive capacity, modeled as generic and specific. While generic adaptive capacity does not account as a direct adaptation cost, it is interesting to compare investments in specific adaptive capacity as opposed to adaptation actions. Figure 6 shows the optimal allocation of resources between adaptation actions and specific adaptive capacity for OECD and non-OECD countries. Investments in both adaptive capacity and adaptation actions constitute a much higher share of GDP in non-OECD countries than in OECD countries. This is because OECD countries overall are less vulnerable to climate change given their higher levels of development and pre-existing levels of 


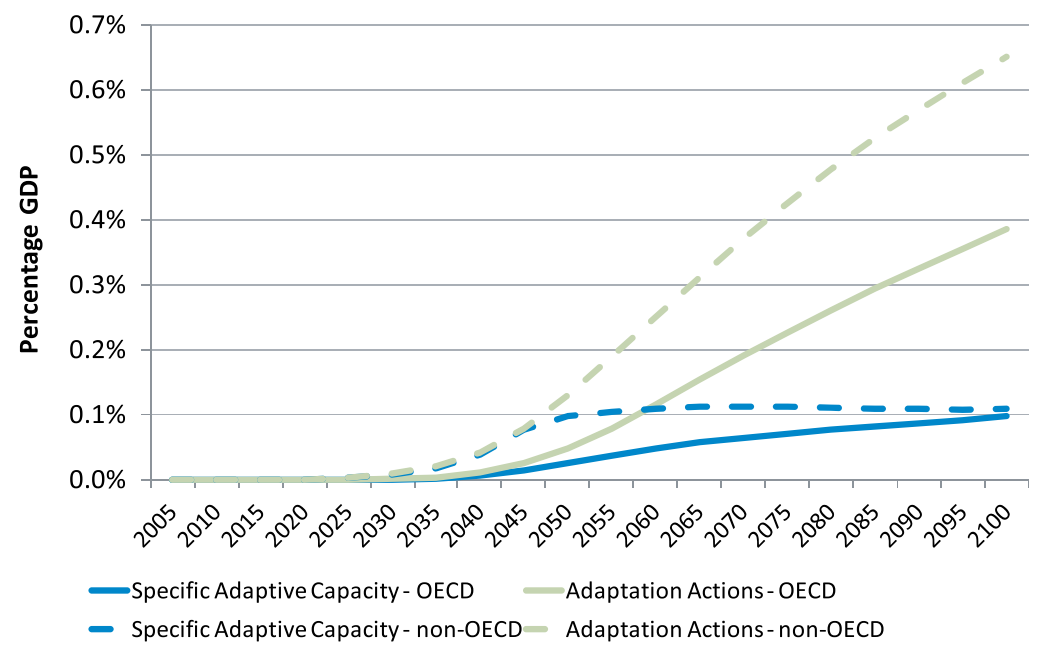

Figure 6. Adaptation actions and adaptive capacity: regional optimal mix.

specific adaptive capacity (such as early warning systems). Further, an optimal adaptation mix in non-OECD countries will consist of almost equal investments in building adaptive capacity and in actions that directly reduce climate damages in the first half of the century. This reflects the considerable adaptation deficit as well as greater exposure to climate change damages in these countries. These regions are more dependent on agriculture and sensitive to health effects. However, once a sufficient level of adaptive capacity is built up, investments in adaptation actions (as opposed to building adaptive capacity) will dominate the strategy mix in both non-OECD and OECD countries in the second half of the century.

\subsection{Interactions between adaptation and mitigation}

A key motivation for including adaptation in IAMs, as mentioned previously, is that it creates the possibility to examine the interactions between adaptation and mitigation. Both mitigation and adaptation help reduce the risks of climate change. Mitigation through the reduction in sources or the enhancement of sinks of greenhouse gases limits climate change and hence its consequences. Adaptation - through adjustments in human and natural systems - reduces the net impacts from changes in climate. IAMs can give us insights into how these two climate controls interact and substitute each other.

To gather quantitative and qualitative insights on the interrelationship between mitigation and adaptation, the effects of mitigation on optimal adaptation patterns are analyzed. The mitigation policy considered here is the stabilizing of $\mathrm{CO}_{2}$-eq concentrations at $550 \mathrm{ppm}$ (corresponding to a temperature of around $2.5^{\circ} \mathrm{C}$ above preindustrial levels at the beginning of the next century). ${ }^{10}$ In order to study the effects of

${ }^{10}$ The $550 \mathrm{ppm}$ target is achieved assuming immediate action and international cooperation. 
such a mitigation policy and its interactions with adaptation expenditures, four different reference scenarios are examined:

- No Control: no adaptation and no mitigation policies;

- Adaptation: scenario with optimal adaptation and no mitigation;

- Mitigation: 550 ppm stabilization without adaptation;

- Adaptation + Mitigation: 550 ppm stabilization with optimal adaptation.

The stabilization level has been chosen purely for illustrative purposes to study the tradeoffs between mitigation and adaptation and should not be viewed as policy prescriptive. The chosen scenarios are meant to reflect a challenging mitigation target. This allows us to verify to what extent adaptation is implemented and how it can complement mitigation efforts. The scenario chosen corresponds roughly to the DICE global optimal scenario (550 versus $590 \mathrm{ppm}$ ).

It is important to clarify the different implementation of adaptation and mitigation policies. While the mitigation target is imposed as an exogenous constraint (e.g., costeffective), adaptation is always chosen on the basis of cost-benefit considerations. In addition, AD-WITCH assumes cooperation only on mitigation while the other externalities are not internalized. Regions are allocated emission permits which can be exchanged in a global carbon market. Global trade equalizes marginal abatement costs, leading to a cost-efficient solution. Given the stabilization target, investments in different energy technologies, physical capital, and $\mathrm{R} \& \mathrm{D}$ are chosen to minimize the costs of achieving this stabilization. In contrast, in the AD-DICE model emission reduction is a choice variable directly controlled by the optimizing social planner, here too other externalities are not internalized.

The Adaptation + Mitigation scenario makes it possible to investigate the potential role of adaptation in the presence of a specific mitigation policy. This approach is consistent with the large majority of climate change policy studies, but it adds adaptation as a new variable. Here, optimal investments in adaptation are chosen, given the optimal mitigation portfolio to achieve the pre-specified $550 \mathrm{ppm}$ stabilization target. Adaptation does not contribute to the achievement of the stabilization target but it contributes to reducing the net climate damages and the total climate costs.

Figure 7 illustrates the individual and joint benefits of mitigation and adaptation policies by comparing residual damage across the four scenarios. ${ }^{11}$ The highest residual damage occurs in the case of complete inaction (i.e., no adaptation or mitigation). When only adaptation or only mitigation is undertaken, the residual damages are intermediate. Meanwhile, the lowest residual damages occur when adaptation and mitigation are used in conjunction. This highlights the complementarity between mitigation and adaptation that was also previously raised by the IPCC Fourth Assessment Report (Fischer et al., 2007).

${ }^{11}$ Note that in the baseline scenario gross damage coincides with residual damage. 

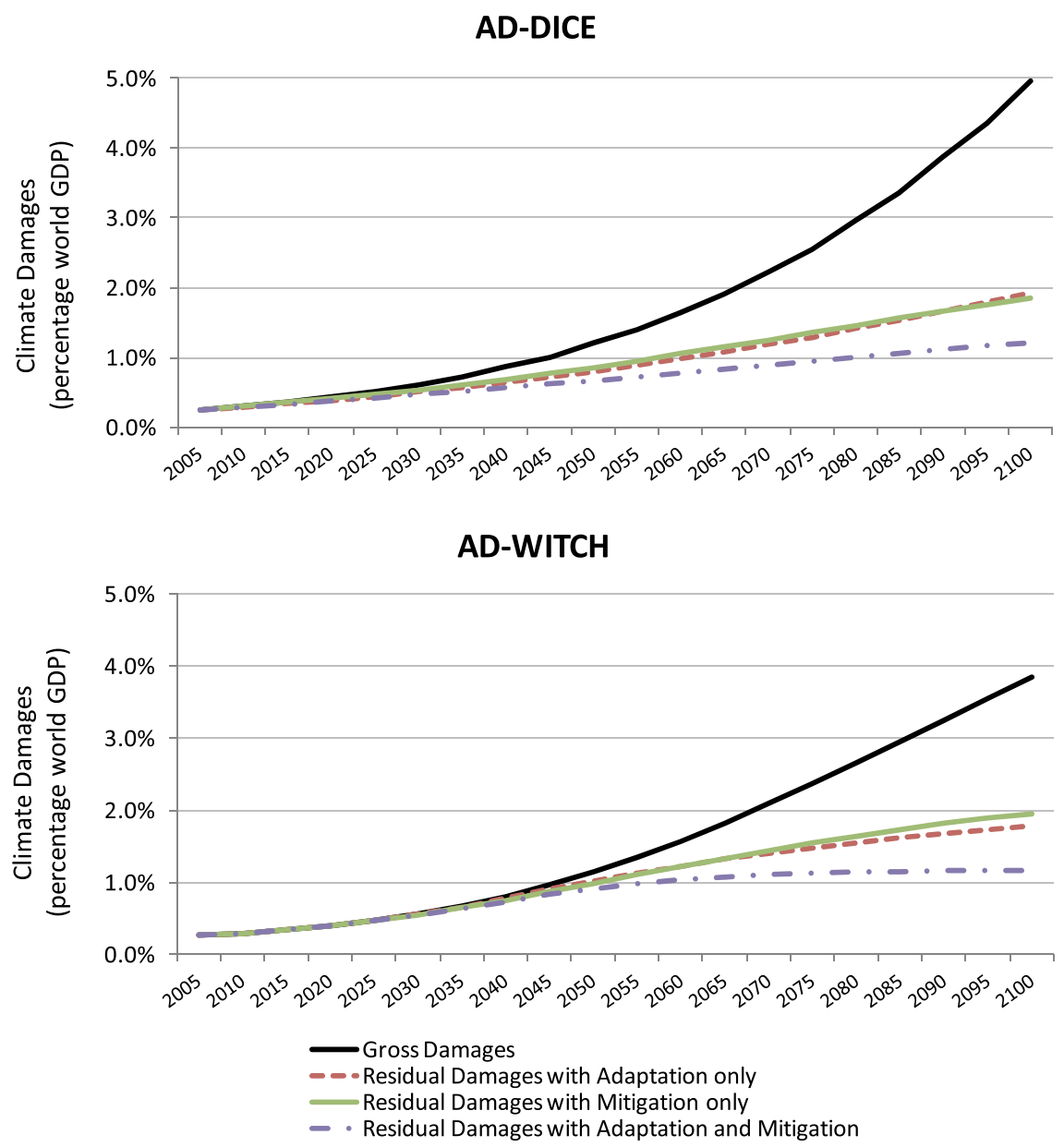

Figure 7. Effect of mitigation and/or adaptation on reducing damages.

Although the results are similar in terms of how mitigation and adaptation reduce climate damages for the two models, the time portfolio of the costs is considerably different. Figure 8 shows the climate change costs (i.e., adaptation and/or mitigation costs plus residual damages) for the three policy scenarios (adaptation only, mitigation only and adaptation plus mitigation). While AD-DICE shows a monotonic build-up in costs under all scenarios, the results are markedly different for the two mitigation scenarios in AD-WITCH where costs build up very quickly early in the present century. This is because in order to achieve the stringent $550 \mathrm{ppm}$ stabilization target, it is necessary to invest in mitigation immediately due to the time lag in realising the benefits of such investments. This effect is present in both models but is much stronger in the AD-WITCH model because of the presence of a disaggregated energy sector and innovative technologies for which it is necessary to invest early.

The dominating influence of the time profile of mitigation costs on the shape of the total cost curve is further illustrated in Fig. 9, which unpacks the total costs for the 

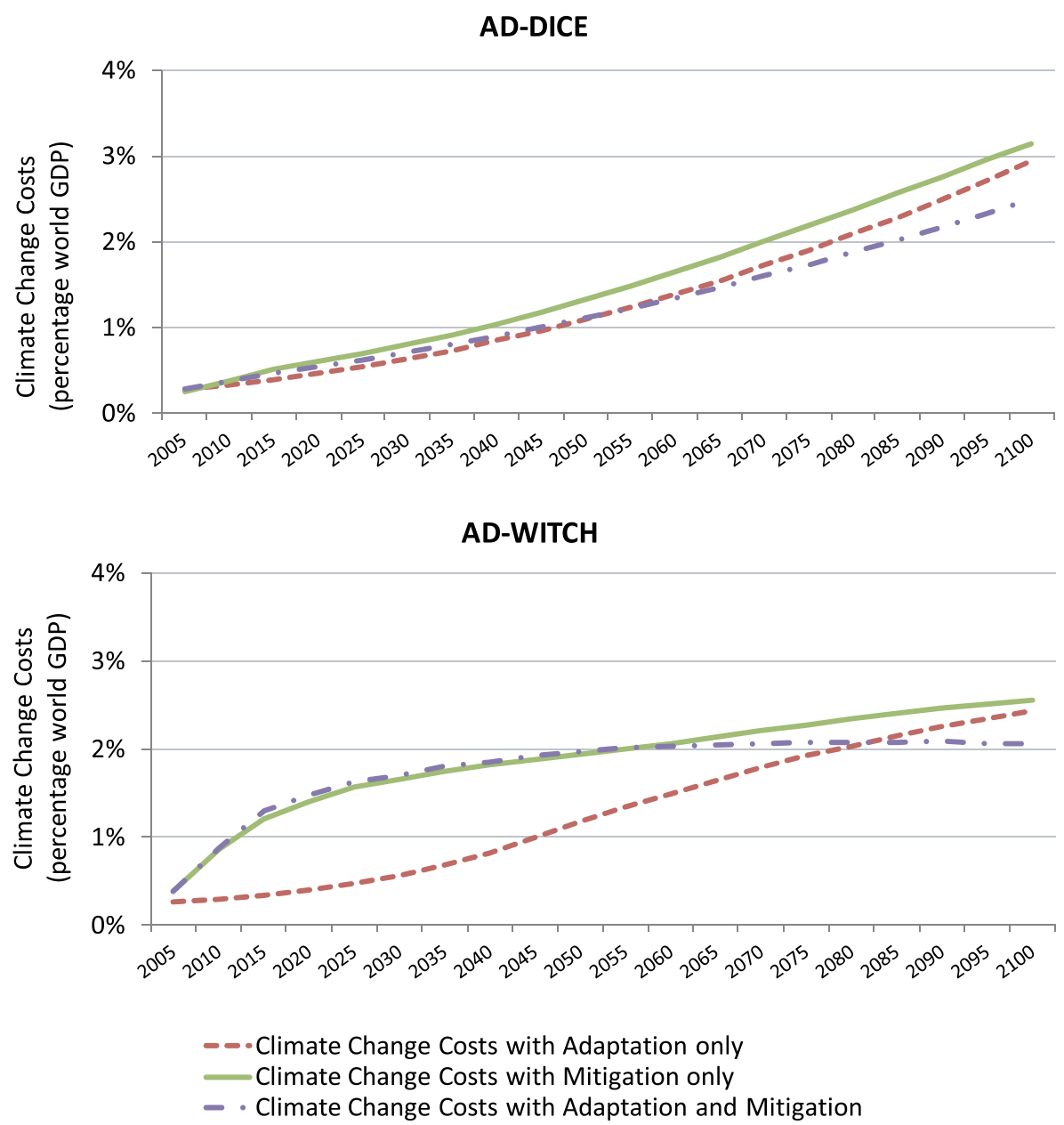

Figure 8 . The costs of climate change for the mitigation and/or adaptation scenarios.

Mitigation + Optimal Adaptation scenario into its three components: adaptation costs, mitigation costs and residual damages. The breakdown of costs, especially for the AD-WITCH model, allows a better understanding of the shape of the total climate change costs curve. Mitigation costs play a large role in determining the shape of the total climate cost curve. As is evident from this figure there is a substantial difference between AD-DICE and AD-WITCH in the time path of mitigation costs. They increase steadily over time in AD-DICE but are higher and skewed at the beginning for ADWITCH, due to the manner in which the model treats mitigation investments. Furthermore, adaptation costs are higher in earlier periods in AD-DICE as adaptation in beneficial from the start, whereas in AD-WITCH, the benefits of adaptation depend on GDP, making adaptation in earlier periods expensive compared to its costs.

The results should not be interpreted as suggesting that mitigation costs are higher in AD-WITCH. The difference is in the timing of the mitigation investments, which are 


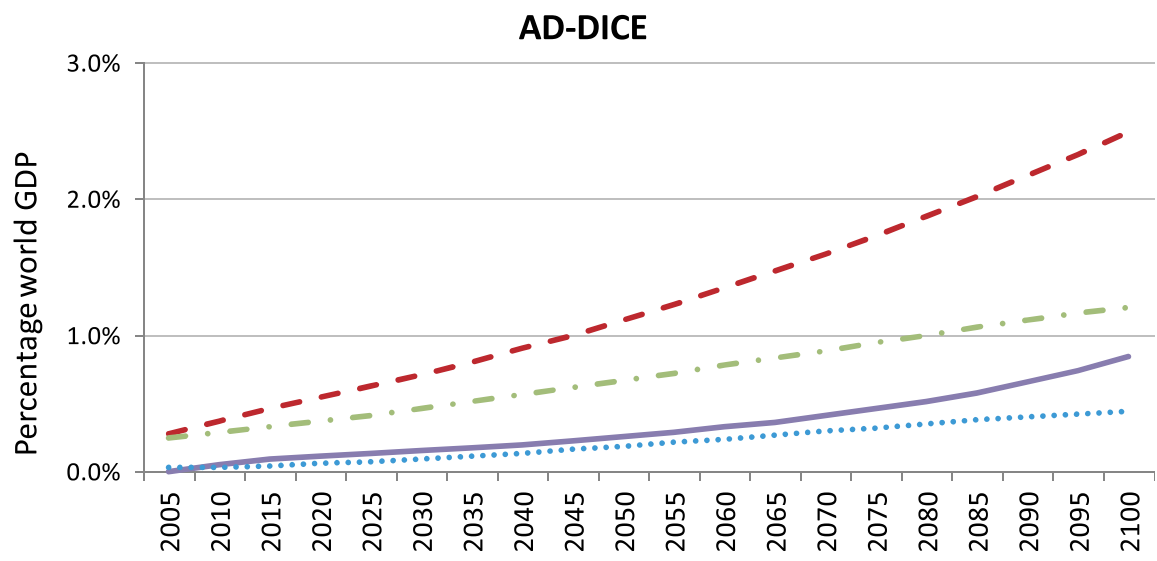

AD-WITCH

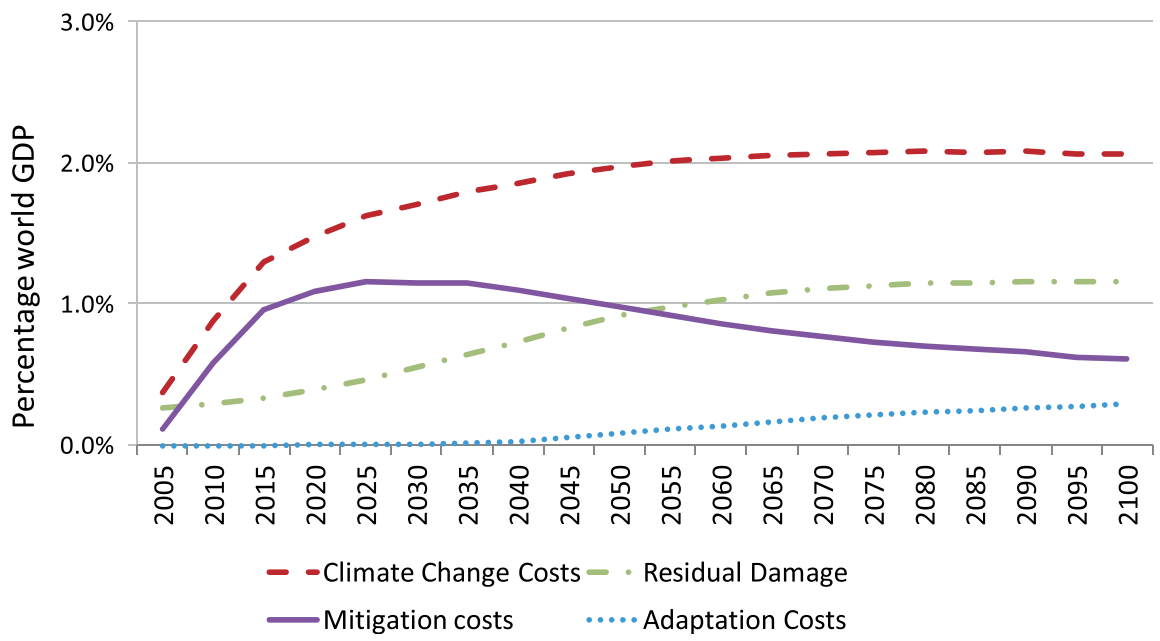

Figure 9. Composition of climate costs in the presence of both adaptation and mitigation.

influenced by the specific assumptions made regarding mitigation as well as the overall time frame considered. The present analysis is limited to the year 2100. If a longer time period were to be considered, mitigation costs would continue to increase in AD-DICE until 2200 and decrease in AD-WITCH.

Finally, this joint analysis of adaptation and mitigation can be used to offer insights on how the level and nature of investments in adaptation are affected by the presence of a (strong) mitigation policy. Figure 10 addresses this question by comparing (in Net Present Value terms) the level and mix of adaptation investments under the Adaptation + Mitigation $(\mathrm{A}+\mathrm{M})$, and the Adaptation (A) only scenarios for AD-DICE and AD-WITCH models.

As shown in Fig. 10, the presence of a strong mitigation policy considerably lowers the optimal level of resources invested in adaptation. Mitigation and adaptation behave as substitutes. This is logical, in part because mitigation and adaptation may compete 


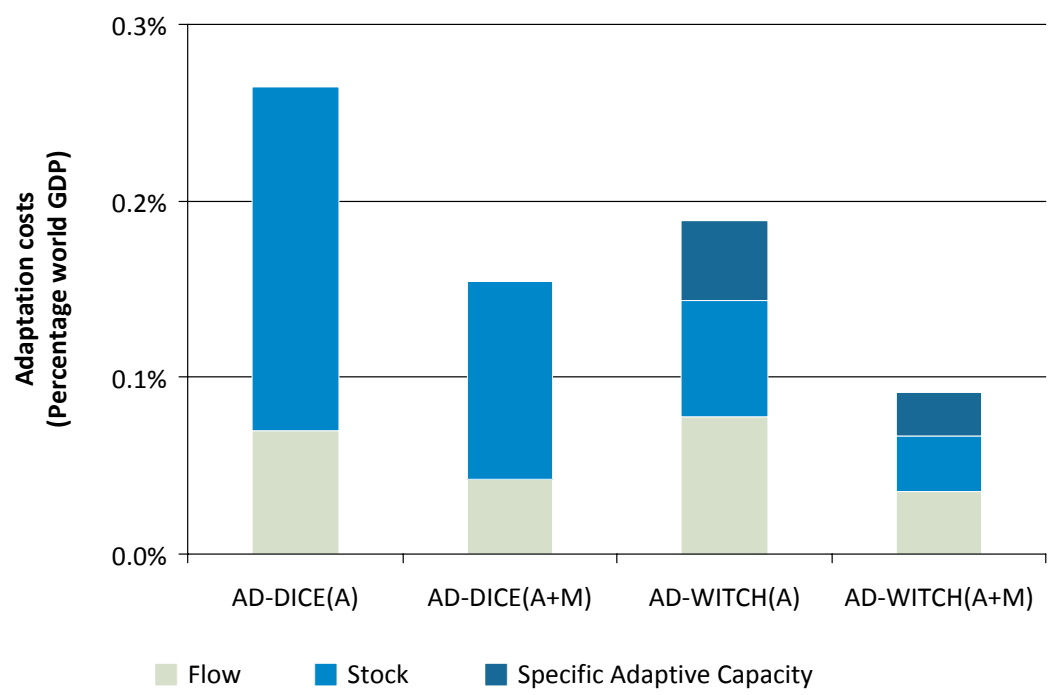

Figure 10. Effect of mitigation on the level and mix of adaptation costs (NPV of climate change costs as percentage of NPV of GDP) (2010-2100 3\% discounting).

for resources but more importantly because stringent mitigation efforts would also reduce climate damages and therefore lower the need for adaptation investments over the long term. The fact that the optimal investment in adaptation declines in the presence of mitigation also illustrates that these two policy levers can be optimally combined to reduce climate change damages. The presence of mitigation also alters the mix of adaptation investments. The share of investment in stock adaptation (and adaptive capacity) is reduced more than for flow adaptation in the presence of mitigation. This effect is particularly pronounced in the case of AD-DICE. Stock adaptation is indeed more similar to mitigation and hence a better substitute, with the need for upfront investments and lagged benefits.

\section{Concluding Remarks}

This paper addresses critical questions with regard to the costs of adaptation and their distribution over time. This is accomplished by developing a framework to incorporate adaptation as a policy variable within the context of two global Integrated Assessment Models (IAMs): DICE and WITCH. These modified models, AD-DICE and $\mathrm{AD}-\mathrm{WITCH}$, are calibrated and then used in a number of policy simulations to examine the composition of adaptation costs, as well as the interaction between adaptation and mitigation. The comparative nature of this assessment facilitates testing the robustness of some of the policy relevant results.

The framework used to model adaptation not only includes treatment of reactive adaptation actions, but also investments in adaptation stocks. Consequently, the dynamic aspects of adaptation, as well as the interactions between adaptation and mitigation are much better addressed in the current framework than in previous works. 
Besides stock and flow adaptation, the adaptation variant of the WITCH model is also used to distinguish between investments in building adaptive capacity and those used for adaptation actions that directly reduce the net climate damages.

This analysis demonstrates that all types of adaptation options as well as adaptive capacity are important in offsetting some of the adverse impacts of climate change. The timing and composition of adaptation interventions is also particularly critical. Investments in adaptation stocks become effective with a time delay, and should ideally be implemented early. Besides the build-up in the stock of adaptation infrastructure, it is equally critical to build up adaptive capacity. Adaptive capacity (both generic and specific to climate change) is currently larger in OECD countries, and this provides the enabling environment to enhance the efficacy of adaptation actions. For non-OECD countries, greater investment in building adaptive capacity would be an essential prerequisite for more effective adaptation downstream. A fundamental challenge facing international policy is how much of this development deficit (such as lack of public health and other infrastructure) should be addressed as part of adaptation financing.

This paper also shows that both mitigation and adaptation are important in responding to climate change and should be part of a climate policy portfolio. The timing of the investments in adaptation and mitigation are also very important. In this respect, the results obtained with the AD-WITCH model, which rely on a more detailed representation of the energy sector, diverge from the AD-DICE results. According to AD-WITCH, significant mitigation expenditure should take place in the near term, because of the inertia in the climate system, as well as the time-lags that are needed to put such investments and capacity in place. On the other hand, according to AD-DICE, gradual build-up of mitigation action is optimal. For adaptation, this implies that there would be a greater emphasis on adaptation in earlier decades in response to the impacts of climatic changes that are already locked-in.

Finally, these models clearly illustrate that the different climate policy options are substitutes yet both needed for the most effective solution to the climate change problem. Any least-cost policy response to climate change will need to involve substantial amounts of mitigation efforts, investments in adaptation stock and reactive adaptation measures to limit the remaining damages. Yet, these options compete for limited resources, and investing heavily in one option will reduce both the budget available for the other policy levers as well as the relative need for other policies. In particular, when optimal levels of action in one of these policies cannot be attained, there are possibilities to limit the excess costs by adjusting the other policies.

There are many potential drawbacks to this study, which should be kept in mind when interpreting the results found. Firstly, though we have highlighted the difference between the models we compare, many of their other assumptions are similar, i.e., their damage functions, climate modules and output functions. This creates a good position from which to compare the effects of the adaptation and mitigation assumption, but it is important to remember that our results also depend on these common assumptions. Secondly, these models do not include certain important issues such as uncertainty, 
irreversibilities and threshold effects. Thirdly, the data on the costs and benefits of adaptation underlying the models is limited. These models therefore cannot be seen as providing perfect policy prescriptions but rather understanding the mechanisms at work concerning adaptation and mitigation. The exact costs and benefits estimated here are only indications and not exact prescriptions of the expected adaptation costs and benefits.

\section{Appendix A. Incorporating Adaptation as a Policy Variable in IAMs}

In this Appendix, the modeling frameworks used in this document are presented in more detail. The incorporation of adaptation in the DICE and WITCH models follows the approach started by de Bruin et al. (2009a,b). In these, the climate change damage function of the DICE and RICE models was unraveled in adaptation costs and residual damages. However, this previous work only considered reactive forms of adaptation (flow adaptation), while the current adaptation-versions of the models (AD-DICE and $\mathrm{AD}-\mathrm{WITCH}$ ) unravel the damage function in residual damages and adaptation costs, where expenditure can be made in both stock and flow adaptation actions. In the ADWITCH model, a further distinction is made between adaptation actions (stock and flow adaptation) and adaptive capacity building, which is composed of generic and specific adaptive capacity. Generic adaptive capacity captures components not necessarily related to adaptation itself but to the economic development of a region. Specific adaptive capacity depends not only on forms of investment such as $R \& D$ and early warning systems, but also on institutional capacity.

In the models gross damages $(G D)$, that are the damages in absence of adaptation, are exponentially linked to temperature changes $(T)$ :

$$
G D_{j, t}=\alpha_{0, j} T_{t}+\alpha_{1, j} T_{t}^{\alpha_{2, j}}
$$

where the subscript $j$ represents the region and the subscript $t$ the time period. In ADDICE gross damages are given as a fraction of GDP. This is one of the most common forms for damage costs of climate change in IAMs (Tol et al. 1998), and it shows the level of climate change damages when no adaptation takes place. In the presence of mitigation, the gross damages decrease.

When adaptation is undertaken, the level of damage is reduced, but not completely, so that there is a residual damage $(R D)$ left. In this case however, there is also an adaptation cost to be paid $(A C)$. The net damage $(N D)$ is then the damage in the presence of adaptation, and it is given by the sum of adaptation costs and residual damage. Expenditure in adaptation can be made in flow adaptation actions (FAD), stock adaptation $(S A D)$, and in the AD-WITCH model also in specific adaptive capacity $(S A C)$.

Flow adaptation entails simultaneous costs and benefits. Stock adaptation instead is created with investments in adaptation (IA). The build up of stock adaptation 
(investment, depreciation) is given by:

$$
S A D_{j, t+1}=(1-\delta) S A D_{j, t}+I A_{j, t}
$$

In this equation, $\delta$ is the capital depreciation rate $(5 \%$ in AD-DICE and $10 \%$ in $\mathrm{AD}-\mathrm{WITCH})$ and $I A$ are the investments in stock adaptation. This means that AD-WITCH puts more emphasis on stock adaptation. The build-up for specific adaptive capacity is also based on the accumulation investments in specific adaptive capacity (IAC), which depreciates at a $3 \%$ rate. ${ }^{12}$ However, our sensitivity analysis of different depreciation rates confirmed the results presented in this paper. Adaptation costs are thus given by:

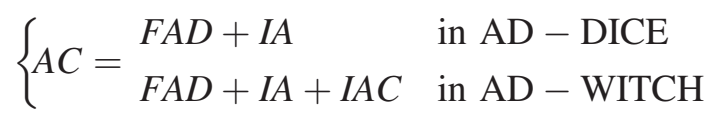

All variables in AD-DICE are given in percentage GDP, while they are in dollars in $\mathrm{AD}-\mathrm{WITCH}$. This is an important difference between the two models, as the level of GDP will influence the decision to adapt in different ways.

Residual damages are linked to gross damages and the achieved level of adaptation (ADAPT) according to the following function: ${ }^{13}$

$$
R D_{j, t}=\frac{G D_{j, t}}{1+A D A P T_{j, t}}
$$

This functional form is chosen because it limits the fraction by which the gross damages can be reduced to the interval of 0 to 1 . When total adaptation reaches infinity, all gross damages are reduced (the residual damages are zero) and when no adaptation is undertaken no gross damages are reduced (residual damages equal gross damages). This functional form also ensures decreasing marginal damage reduction of adaptation, that is the more adaptation is used the less effective additional adaptation will be. Thus, efficient measures of adaptation will first be applied whereas less effective measures will be used later.

Flow adaptation and investment in stock adaptation are aggregated together to adaptation actions (ACT) using a Constant Elasticity of Substitution (CES) function:

$$
A C T_{j, t}=\beta_{1, j}\left(\beta_{2, j} F A D_{j, t}^{\rho}+\left(1-\beta_{2, j}\right) S A D_{j, t}^{\rho}\right)^{\frac{\beta_{3}}{\rho}}
$$

In AD-DICE adaptation, strategies coincide with overall adaptation (ADAPT). Thus, for AD-DICE adaptation coincides with the actions, so that $A D A P T=A C T$. In

\footnotetext{
${ }^{12}$ Direct stock adaptation is comparable to building or adapting infrastructure so it is a capital-intensive activity which is assumed to depreciate at a rate close to that of physical capital. Specific adaptive capacity instead is assumed to depreciate at a lower rate because it has a knowledge component that is therefore closer to human capital, which depreciates at a lower rate.

${ }^{13}$ De Bruin et al. (2009b) provide some insight into the implications of this functional form and contrast it with a specification of $R D=(1-P) * G D$ and find that the differences are limited.
} 
AD-WITCH however, adaptation actions are part of a bigger nest in which they are combined with adaptive capacity building. Adaptive capacity is also derived as a CES combination of specific $(S A D)$ and generic $(G A D)$ adaptive capacity:

$$
A C_{j, t}=\left(\varphi_{j} S A C_{j, t}^{\gamma}+\left(1-\varphi_{j}\right) G A C_{j, t}^{\gamma}\right)^{\frac{1}{\gamma}}
$$

Finally, adaptation actions and adaptive capacity building are combined to form total adaptation, also with a CES function:

$$
A D A P T_{j, t}=\left(\mu_{j} A C T_{j, t}^{\gamma}+\left(1-\mu_{j}\right) A C_{j, t}^{\gamma}\right)^{\frac{1}{\rho}}
$$

The chosen values for the elasticities of substitution are not the same between the models. In absence of empirical estimates for such elasticities, the values have been chosen to reflect substitutability between the different adaptation types. However, because there is a low value of substitution all forms of adaptation will be necessary for an optimal policy. AD-DICE assumes an elasticity of substitution between stock and flow adaptation equal to 2, so that the exponential parameter $\rho$ in the CES function is 0.5. This means that in the baseline, when only one adaptation option is available, adaptation expenditures will need to almost double to achieve the same level of adaptation as when both forms of adaptation are applied. Note that this substitutability not only reflects the choice between stock and flow in one damage category but also the substitution between damage categories. For example if stock adaptation is not available, less damage will be reduced in the coastal sector and more in a sector with a large potential to apply flow adaptation. The elasticity of substitution in AD-WITCH is instead 1.2, with an exponential parameter $\rho$ equal to 0.2 . This is due to the fact that the stock and flow adaptation actions are part of a bigger nest in the AD-WITCH model. Specific and generic adaptive capacities are assumed to be gross complements with an elasticity of substitution equal to 0.2. Adaptive capacity building and adaptation actions are instead assumed to be gross substitutes and have an elasticity of substitution of 1.2 .

\section{Appendix B. Comparison of the Models' Data Sources and Assumptions}

The calibration of the models aims to account for output losses due to climate change and includes both costs of adaptation and residual damages. The models are parameterized to replicate the net damages. The parameterization is based on the adaptation costs, the efficiency of adaptation (the potential of adaptation expenditure to reduce gross damages), and total damages from adaptation.

There are different initial assumptions on the division between stock and flow adaptation in the two models. As already underlined, the two models differ in their assumptions on stock and flow adaptation. On one hand, AD-DICE always split the overall expenditure in stock and flow. On the other hand, AD-WITCH mostly assigns to each category an expenditure type, which is the prevalent one in that category. Table B.1 summarizes the stock and flow modeling differences. 
Table B.1. Stock and flow adaptation.

\begin{tabular}{lll}
\hline & \multicolumn{1}{c}{ AD-DICE } & \multicolumn{1}{c}{ AD-WITCH } \\
\hline Agriculture & Stock \& Flow (both highly relevant) & Stock \\
Other Vulnerable Markets & Stock \& Flow (prevalently flow) & Stock \& Flow \\
Catastrophic Events & Stock \& Flow (both highly relevant) & Adaptive Capacity \\
Coastal Systems & Stock \& Flow (prevalently stock) & Stock \\
Settlements & Stock \& Flow (prevalently stock) & Stock \\
Non-Market Time Use & Stock \& Flow (prevalently stock) & Flow \\
Health & Stock \& Flow (prevalently flow) & Flow \\
\hline
\end{tabular}

The two models have similar assumptions on the effectiveness of adaptation in the various sectors considered. A few differences are due to the different sources used for the calibration. Table B.2 lists the different sources used. The main differences are in the assumptions made relative to agriculture, due to the differences in the stock and flow modeling of this sector.

Other differences can be found in the way the two models calibrate adaptation costs. Whereas assumptions are similar for a number of sectors, such as settlements and nonmarket time use, they are different for others, such as coastal systems, for which

Table B.2. Effectiveness of adaptation.

\begin{tabular}{|c|c|c|}
\hline Sector & AD-DICE & AD-WITCH \\
\hline Agriculture & $\begin{array}{l}\text { Implementation of adaptation } \\
\text { measures can be very effective } \\
\text { in this sector. } \\
\text { Source: Tan and Shibasaki } \\
\text { (2003), Rosenzweig and } \\
\text { Parry (1994), Nordhaus and } \\
\text { Boyer (2000) }\end{array}$ & $\begin{array}{l}\text { Medium levels of effectiveness for } \\
\text { agricultural measures. High level } \\
\text { of effectiveness for water } \\
\text { infrastructures. } \\
\text { Source: Tan and Shibasaki (2003), } \\
\text { EEA (2007), Kirshen et al. (2006) }\end{array}$ \\
\hline Other Vulnerable Markets & $\begin{array}{l}\text { High effectiveness of air } \\
\text { conditioning in offsetting the } \\
\text { negative impacts of increasing } \\
\text { temperatures. } \\
\text { Source: Martens (1998), } \\
\text { Gawith } \text { et al. (1999) }\end{array}$ & $\begin{array}{l}\text { High effectiveness of air conditioning } \\
\text { in offsetting the negative impacts } \\
\text { of increasing temperatures in } \\
\text { developed countries, medium in } \\
\text { developing countries. } \\
\text { Source: ad hoc assumptions }\end{array}$ \\
\hline Catastrophic Events & $\begin{array}{l}\text { Low level of effectiveness due to } \\
\text { the actual catastrophic } \\
\text { consequences of extreme } \\
\text { events. } \\
\text { Source: Nordhaus and Boyer } \\
\text { (2000), ad hoc assumptions }\end{array}$ & $\begin{array}{l}\text { No adaptation possibility for } \\
\text { catastrophic events is considered. } \\
\text { Source: Nordhaus and Boyer } \\
\text { (2000), ad hoc assumptions }\end{array}$ \\
\hline Coastal Systems & $\begin{array}{l}\text { High effectiveness of coastal } \\
\text { infrastructures } \\
\text { Source: FUND model } \\
\text { (Tol, 2007) }\end{array}$ & $\begin{array}{l}\text { High effectiveness of coastal } \\
\text { infrastructures. } \\
\text { Source: DIVA model }\end{array}$ \\
\hline
\end{tabular}


Table B.2. (Continued)

\begin{tabular}{|c|c|c|}
\hline Sector & AD-DICE & AD-WITCH \\
\hline Settlements & $\begin{array}{l}\text { Low effectiveness for } \\
\text { ecosystems, medium-high for } \\
\text { human settlements as } \\
\text { migration is considered as an } \\
\text { option. } \\
\text { Source: Nordhaus and Boyer } \\
\text { (2000), ad hoc assumptions }\end{array}$ & $\begin{array}{l}\text { No effectiveness for ecosystems, high } \\
\text { for human settlements as migration } \\
\text { is considered as an option. } \\
\text { Source: Nordhaus and Boyer } \\
\text { (2000), DIVA model }\end{array}$ \\
\hline Non-Market Time Use & $\begin{array}{l}\text { High level of effectiveness, due } \\
\text { to the fact that adaptation will } \\
\text { depend simply on adjusting } \\
\text { individual's activities. } \\
\text { Source: Nordhaus and Boyer } \\
\text { (2000), ad hoc assumptions }\end{array}$ & $\begin{array}{l}\text { High level of effectiveness, due to the } \\
\text { fact that adaptation will depend } \\
\text { simply on adjusting individual's } \\
\text { activities. } \\
\text { Source: Nordhaus and Boyer } \\
\text { (2000), ad hoc assumptions }\end{array}$ \\
\hline Health & $\begin{array}{l}\text { Medium-high level of } \\
\text { effectiveness of adaptation: it } \\
\text { is high for certain measures } \\
\text { like disease treatment but low } \\
\text { for others such as air pollution. } \\
\text { Source: WHO (2008), } \\
\text { Murray and Lopez (1996) }\end{array}$ & $\begin{array}{l}\text { Medium-high level of effectiveness of } \\
\text { adaptation: it is high for certain } \\
\text { measures like disease treatment but } \\
\text { low for others such as air pollution. } \\
\text { Source: WHO (2008) }\end{array}$ \\
\hline
\end{tabular}

different models are used, or health and catastrophic events. In these sectors, the differences are often dependent on the fact that some measures considered in AD-DICE are instead part of adaptive capacity in AD-WITCH. Other differences depend again on the literature sources used as illustrated in Table B.3.

Table B.3. Adaptation costs.

\begin{tabular}{|c|c|c|}
\hline Sector & AD-DICE & AD-WITCH \\
\hline Agriculture & $\begin{array}{l}\text { Costs of changes in plant timing, } \\
\text { irrigation, fertilization and } \\
\text { development of new varieties. } \\
\text { Adaptation costs are estimated } \\
\text { to be low. } \\
\text { Source: Tan and Shibasaki (2003), } \\
\text { Rosenzweig and Parry (1994) }\end{array}$ & $\begin{array}{l}\text { Costs of changes in plant timing, } \\
\text { irrigation, fertilization and } \\
\text { development of new varieties. } \\
\text { Adaptation costs are } \\
\text { estimated to be low for } \\
\text { developed countries, higher in } \\
\text { other countries, especially in } \\
\text { Middle East, Africa and } \\
\text { transition economies. } \\
\text { Source: Tan and Shibasaki } \\
\text { (2003), Parry et al. }(2009)\end{array}$ \\
\hline
\end{tabular}


Table B.3. (Continued)

\begin{tabular}{|c|c|c|}
\hline Sector & AD-DICE & AD-WITCH \\
\hline Other Vulnerable Markets & $\begin{array}{l}\text { Differences in energy demand } \\
\text { and their costs. } \\
\text { Source: Cline (1992), Nordhaus } \\
\text { (1991), Mendelsohn and } \\
\text { Neumann (1999) }\end{array}$ & $\begin{array}{l}\text { Differences in energy demand } \\
\text { and their costs. } \\
\text { Source: Tol (2002, 2002a), } \\
\text { Bigano et al. (2006), De Cian } \\
\text { et al. } \text { (2007). Changes in } \\
\text { water infrastructures } \\
\text { necessary to meet water } \\
\text { demand. } \\
\text { Source: Kirshen (2007) }\end{array}$ \\
\hline Catastrophic Events & $\begin{array}{l}\text { The high costs of catastrophic events are } \\
\text { weighted by the probabilities of } \\
\text { them happening. Expenditure in } \\
\text { early warning systems is included. } \\
\text { Source: Nordhaus and Boyer (2000), } \\
\text { ad hoc assumptions }\end{array}$ & $\begin{array}{l}\text { The high costs of catastrophic } \\
\text { events are weighted by the } \\
\text { probabilities of them } \\
\text { happening. Early warning } \\
\text { systems are not considered } \\
\text { here but as part of adaptive } \\
\text { capacity measures. } \\
\text { Source: Nordhaus and Boyer } \\
\text { (2000), ad hoc assumptions }\end{array}$ \\
\hline Coastal Systems & $\begin{array}{l}\text { Costs estimation based on the FUND } \\
\text { model. } \\
\text { Source: Tol (2007) }\end{array}$ & $\begin{array}{l}\text { Costs estimation based on the } \\
\text { DIVA model. }\end{array}$ \\
\hline Settlements & $\begin{array}{l}\text { Adaptation costs are considered to be } \\
\text { high for both settlements and } \\
\text { ecosystems. For settlements this is } \\
\text { derived by the difficulties in adapting } \\
\text { existing cities (e.g., Venice). } \\
\text { Source: Nordhaus and Boyer (2000), } \\
\text { ad hoc assumptions }\end{array}$ & $\begin{array}{l}\text { Adaptation costs are considered } \\
\text { to be high for both settlements } \\
\text { and ecosystems. For } \\
\text { settlements this is derived by } \\
\text { the difficulties in adapting } \\
\text { existing cities (e.g., Venice). } \\
\text { Source: Nordhaus and } \\
\text { Boyer (2000), ad hoc } \\
\text { assumptions }\end{array}$ \\
\hline Non-Market Time Use & $\begin{array}{l}\text { Adaptation is assumed to be virtually } \\
\text { cost free, as it consists in adjustment } \\
\text { in activities. } \\
\text { Source: Own assumption }\end{array}$ & $\begin{array}{l}\text { Adaptation is assumed to be } \\
\text { virtually cost free, as it } \\
\text { consists in adjustment in } \\
\text { activities. } \\
\text { Source: Own assumption }\end{array}$ \\
\hline Health & $\begin{array}{l}\text { Treatment costs associated to } \\
\text { climate-related illnesses and costs of } \\
\text { health infrastructures. While the first } \\
\text { have low costs, the latter have higher } \\
\text { costs. } \\
\text { Source: WHO (2008), Murray and } \\
\text { Lopez (1996) }\end{array}$ & $\begin{array}{l}\text { Treatment costs associated to } \\
\text { climate-related illnesses. The } \\
\text { costs of adaptation options are } \\
\text { low. Health infrastructures are } \\
\text { not considered here but as } \\
\text { part of adaptive capacity. } \\
\text { Source: Tol and Dowlatabadi } \\
\text { (2001) }\end{array}$ \\
\hline
\end{tabular}




\section{Appendix C. Models Baseline Comparison}

In this section, the baselines of AD-DICE and AD-WITCH are compared with the common Special Report on Emissions Scenarios (SRES) ${ }^{14}$ storylines developed by the IPCC. Comparisons are made along three projections: emissions, temperature change, and output, illustrated respectively in Figs. C.1, C.2 and C.3. Projections of emissions are made to verify that the models predict the same levels of emissions in the baseline. Temperature change comparisons are used to verify that these emissions are translated into temperature change in the same range in AD-DICE and AD-WITCH as they are in SRES. Finally, projections of output are compared to verify that the economic expectations given climate change are in the same range.

As can be seen from the figures, the AD-DICE and AD-WITCH baselines are similar. They generally fall within the SRES range and are closest to the B scenarios. Temperature and output estimates are particularly close to the B2 scenario.

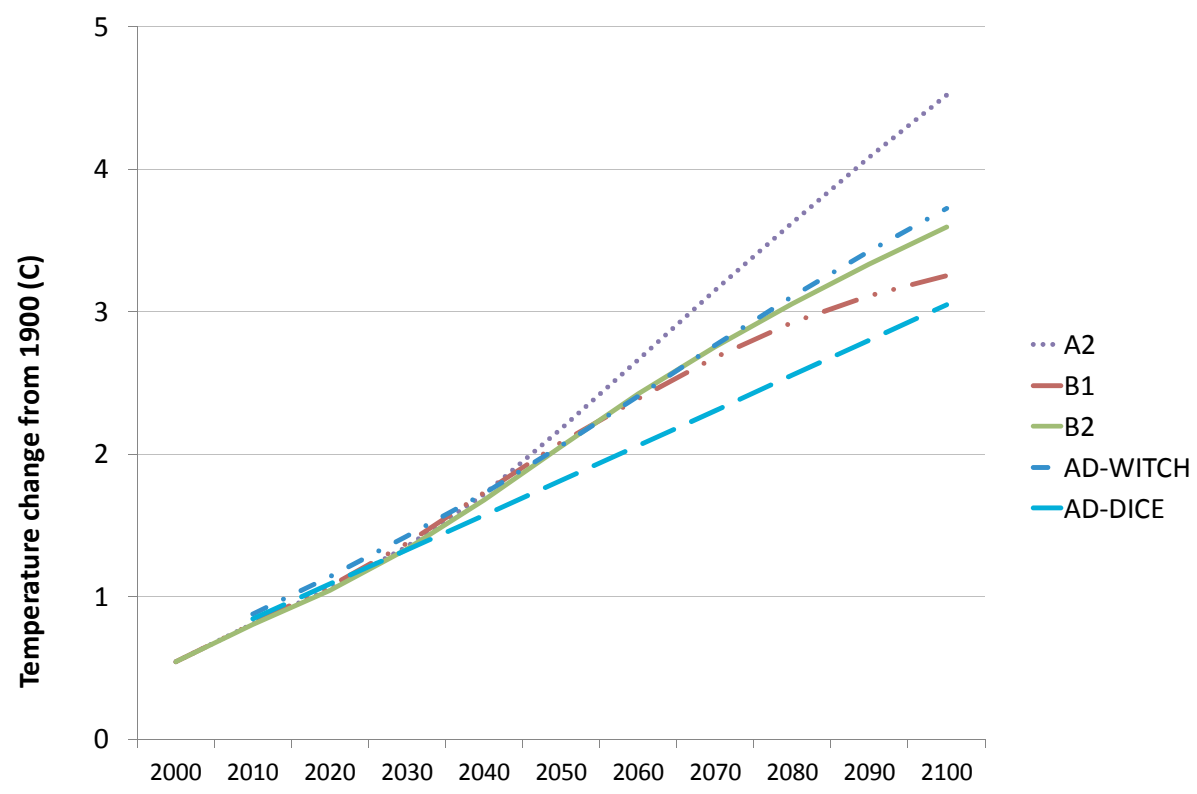

Figure C.1. Temperature in the models baseline scenarios compared to IPCC SRES.

\footnotetext{
${ }^{14}$ Climate models are usually run against scenarios that reflect different levels of human activity. The various SRES scenarios are based on different assumptions on future pollution, land use, and other driving forces. The A2 scenario reflects a divided world in which nations are self-reliant, economically oriented, and not environment-focused. The B1 scenario reflects instead a more integrated and ecologically friendly world in which there is resource-saving technical change, and a slower population growth. Finally, the B2 scenario is also ecologically friendly, but with less coordination between countries and more focus on local solutions.
} 


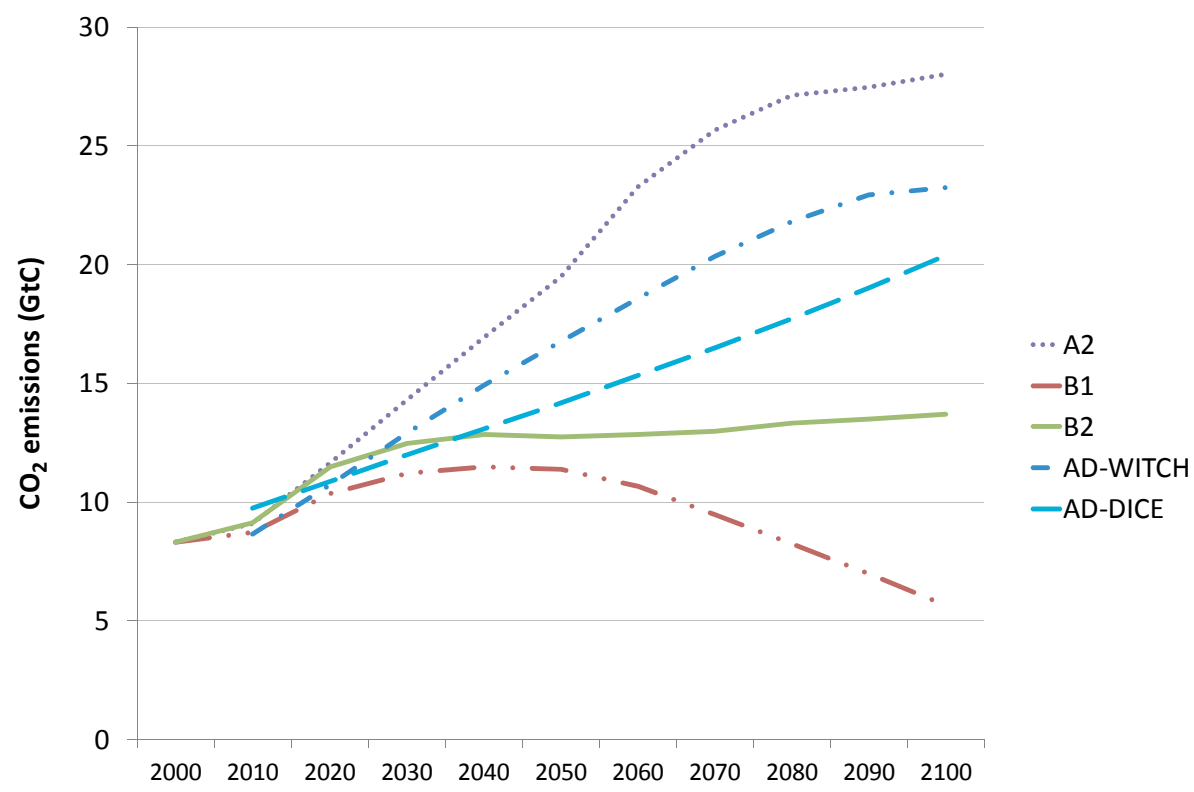

Figure C.2. Emissions in the models baseline scenarios compared to IPCC SRES.

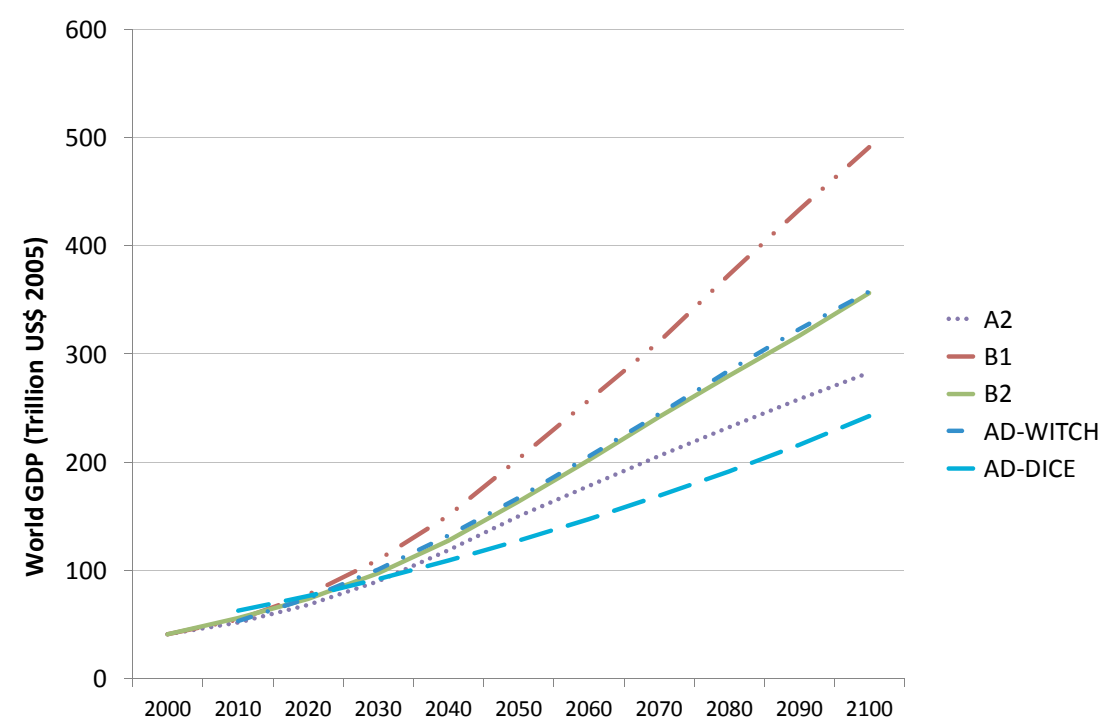

Figure C.3. World GDP in the models baseline scenarios compared to IPCC SRES. 


\section{References}

Adams, RM, LL Houston and BA McCarl (2000). The benefits to Mexican agriculture of an El Niño-southern oscillation (ENSO) early warning system. Agricultural and Forest Meteorology, 115, 183-194.

Agrawala, S and S Fankhauser (2008). Economics Aspects of Adaptation to Climate Change. Costs, Benefits and Policy Instrument. OECD, Paris.

Agrawala, S, F Bosello, C Carraro, K de Bruin, E De Cian, R Dellink and E Lanzi (2010). Plan or React? Analysis of Adaptation Costs and Benefits Using Integrated Assessment Models, OECD Environment Working Papers, No. 23, OECD, Paris.

Bigano, A, F Bosello and G Marano (2006). Energy Demand and Temperature: A Dynamic Panel Analysis, FEEM Working Paper No. 112.06.

Bosello, F (2010). Adaptation, Mitigation and “Green” R\&D to Combat Global Climate Change. Insights From an Empirical Integrated Assessment Exercise, FEEM Working Paper 2010.022.

Bosello, F, C Carraro and E De Cian (2010). Climate policy and the optimal balance between mitigation, adaptation and unavoided damage. Climate Change Economics, 1(02), 71-92.

Bosetti, V, C Carraro, M Galeotti, E Massetti and M Tavoni (2006). WITCH: A world induced technical change hybrid model. The Energy Journal, Special Issue on Hybrid Modeling of Energy-Environment Policies: Reconciling Bottom-up and Top-down, 13-38.

Bosetti, V, C Carraro and M Galeotti (2006a). The dynamics of carbon and energy intensity in a model of endogenous technical change. The Energy Journal, Special Issue on Endogenous Technological Change and the Economics of Atmospheric Stabilization, 221-256.

Bosetti, V, E Massetti and M Tavoni (2007). The WITCH Model: Structure, Baseline, Solutions, FEEM Working Paper 10-2007, Milan.

Bosetti, V, E De Cian, A Sgobbi and M Tavoni (2009). The 2008 WITCH Model: New Model Features and Baseline, FEEM Working Paper No. 085.2009.

Clarke et al. (2007). Special Issue on Endogenous Technological Change and the Economics of Atmospheric Stabilization, 191-206.

Cline, W (1992). The Economics of Global Warming. Institute for International Economics, Washington, DC.

de Bruin, KC, RB Dellink and S Agrawala (2009a). Economic Aspects of Adaptation to Climate Change: Integrated Assessment Modelling of Adaptation Costs and Benefits, OECD Environment Working Paper, No. 6.

de Bruin, KC, RB Dellink and R Tol (2009b), AD-DICE: An implementation of adaptation in the DICE model. Climatic Change, 95(1-2), 63-81.

de Bruin, KC, RB Dellink, RSJ Tol (2009c). International Cooperation on Climate Change Adaptation from an Economic Perspective, ESRI Working Paper 323, Dublin.

de Bruin, KC and RB Dellink (2011). How harmful are restrictions on adapting to climate change? Global Environmental Change, 21, 34-45.

de Bruin, KC (2011). Distinguishing Between Proactive (Stock) and Reactive (Flow) Adaptation, CERE Working Paper, 2011:8.

De Cian, E, E Lanzi and R Roson (2007). The Impact of Temperature Change on Energy Demand: A Dynamic Panel Analysis, FEEM Working Paper 46/2007, Milan.

European Environment Agency (EEA) (2007). Climate Change: The Cost of Inaction and the Cost of Adaptation, EEA Technical Report, No. 13/2007.

Fankhauser, S (1994). Protection vs. retreat - The economic costs of sea level rise. Environmental and Plan, 27, 99-319.

Fankhauser, S (1995). Valuing Climate Change. The Economics of the Greenhouse, London: Earthscan. 
Fankhauser, S, JB Smith and RSJ Tol (1999). Weathering climate change: Some simple rules to guide adaptation decisions. Ecological Economics, 30, 67-78.

Fischer, G, K Frohberg, ML Parry and C Rosenzweig (1993). Climate Change and World Food Supply, Demand and Trade, in Costs, Impacts, and Benefits of CO2 Mitigation. In Kaya et al. (eds.), pp. 133-152.

Fischer, G, FN Tubiello, H van Velthuizen and DA Wiberg (2007). Climate change impacts on irrigation water requirements: Effects of mitigation 1990-2080. Technological Forecasting and Social Change, 74, 1083-1107.

Gawith, MJ, TE Downing and TS Karacostas (1999). Heatwaves in a Changing Climate. In Climate, Change and Risk, Downing, AA Olsthoorn and RSJ Tol (eds.). London: Routledge.

Hope, C, J Anderson and P Wenman (1993). Policy analysis of the greenhouse effect-an application of the PAGE model. Energy Policy, 15, 328-338.

IPCC (2001). Climate Change 2001: Impacts, Adaptation and Vulnerability, Contribution of Working Group II to the Third Assessment Report of the Intergovernmental Panel on Climate Change. Cambridge University Press.

IPCC (2007). Climate Change 2007: Contribution of Working Group II to the Fourth Assessment Report of the Intergovernmental Panel on Climate Change. Cambridge University Press.

Kirshen, P, M Ruth and W Anderson (2006). Climate's long-term impacts on urban infrastructures and services: The case of Metro Boston. In Regional Climate Change and Variability: Impacts and Responses, Ruth, M, K Donaghy and P Kirshen (eds.), 190-252. Northampton, MA: Edward Elgar.

Kirshen, P (2007). Adaptation Options and Coast of Water Supply. Tuft University, MA.

Lecocq, F and Z Shalizi (2007). Balancing Expenditures on Mitigation of Adaptation to Climate Change: An Exploration of Issues Relevant to Developing Countries, Policy Research Working Paper Series 4299, The World Bank.

Mendelsohn, R (2000). Efficient adaptation to climate change. Climatic Change, 45, 583-600.

Mendelsohn, R and J Neumann (eds.) (1999). The Impact of Climate Change on the United States Economy. Cambridge: Cambridge University Press.

Murray, CJL and AD Lopez (1996). The Global Burden of Disease, Geneva, World Health Organization, Harvard School of Public Health, World Bank.

Nordhaus, WD (1991). To slow or not to slow: The economics of the greenhouse effect. The economic Journal, 101(407), 920-937.

Nordhaus, WD (1994). Managing the Global Commons: The Economics of the Greenhouse Effect. Cambridge, MA: MIT Press.

Nordhaus, WD and J Boyer (2000). Warming the World. Economic Models of Global Warming. Cambridge, MA: The MIT Press.

Nordhaus, WD and Z Yang (1996). A regional dynamic general-equilibrium model of alternative climate change strategies. American Economic Review, 4, 741-765.

Parry, M, N Arnell, P Berry, D Dodman, S Fankhauser, C Hope, S Kovats and R Nicholls (2009). Assessing the Costs of Adaptation to Climate Change. London: Imperial College.

Popp, D (2004). ENTICE: Endogenous Technical Change in de DICE Model of Global Warming, NBER Working Paper 9762, National Bureau of Economic Research, Cambridge, USA.

Rosenthal, DH, HK Gruenspecht and E Moran (1995). Effects of Global Warming on Energy Use for Space Heating and Cooling in the United States, U.S. Department of Energy, Washington, DC.

Rosenzweig, C and ML Parry (1994). Potential impact of climate change on world food supply. Nature, 367, 133-138. 
Stern, N (2007). The Economics of Climate Change. The Stern Review, Cambridge University Press.

Tan, G and R Shibasaki (2003). Global estimation of crop productivity and the impacts of global warming by GIS and EPIC integration. Ecological Modelling, 168, 357-370.

Tol, RSJ and H Dowlatabadi (2001). Vector-borne diseases, development and climate change. Integrated Assessment, 2, 173-181.

Tol, RSJ (2005). Adaptation and mitigation: Trade-offs in substance and methods. Environmental Science and Policy, 8, 572-578.

Tol, RSJ (2007). The double trade-off between adaptation and mitigation for sea level rise: An application of FUND. Mitigation and Adaptation Strategies for Global Change, 12, $741-753$.

UNFCCC (2007). Investments and Financial Flows to Address Climate Change. Background paper on analysis of existing and planned investments and financial flows relevant to the development of effective and appropriate international response to climate change, p. 273.

Yohe, GW and M Schlesinger (1998). Sea-level change: The expected economic cost of protection or abandonment in the United States. Climatic Change, 38, 437-472.

WHO (2008). World Health Organisation Malaria Report 2008, WHO/HTM/GMP/2008.1, (http://www.who.int/malaria/wmr2008/malaria2008.pdf).

World Bank (2010). The Costs to Developing Countries of Adapting to Climate Change: New Methods and Estimates, The Global Report of the Economics of Adaptation to Climate Change Study. 